\title{
Correspondence and Brief Communications
}

Correspondence and brief communications are welcomed and need not concern only what has been published in this journal. We shall print items of interest to our readers, such as experimental, clinical, and philosophical observations; reports of work in progress; educational notes; and travel accounts relevant to plastic surgery. We reserve the right to edit communications to meet requirements of space and format. Any financial interest relevant to the content of the correspondence must be disclosed. Submission of a letter constitutes permission for the American Society of Plastic Surgeons and its licensees and assignees to publish it in the journal and in any other form or medium.

The views, opinions, and conclusions expressed in the Letters to the Editor represent the personal opinions of the individual writers and not those of the publisher, the Editorial Board, or the sponsors of the journal. Any stated views, opinions, and conclusions do not reflect the policy of any of the sponsoring organizations or of the institutions with which the writer is affiliated, and the publisher, the Editorial Board, and the sponsoring organizations assume no responsibility for the content of such letters.

\section{JUST STOP OR JUST COMPLAIN}

Sir:

Dr. Sean Boutros makes a well-intentioned plea for a positive outlook on plastic surgery in "Just Stop" (Plast. Reconstr. Surg. 111: 1355, 2003), but we offer slightly different advice to our colleagues. To those who are currently quiet, please just complain. To those who are already speaking out, please be more vociferous!

What is the line that demarcates complaint and advocacy? Are we complaining when we argue for a patient to receive a breast reduction to relieve pain? Is it complaining when a breast cancer survivor needs our support to undergo a procedure to restore her sense of femininity? Should we be silent when many of us waste billions of dollars on defensive medicine lest we be sued for leaving some pebble unturned? Why should we not speak out when we are forced to dictate notes to fill a relatively capricious Evaluation and Management template checklist as opposed to providing real care? Is it being bitter when we write second and third letters of appeal to managed care companies as our patients' ombudsman?

These difficulties are part of medicine's complex landscape. We have chosen to love this profession despite all its difficulties, but with that choice, we have also undertaken a responsibility to change the status quo. It is our duty to complain or, at the very least, to support those who advocate on our behalf. As members of several plastic surgery and medical societies, we joined organizations of colleagues and compatriots who, precisely because they do complain, protect the integrity of our field. Our dues pay to organize these "complaints" so that they may champion our rights and those of our patients as effectively as possible, protecting them from charlatans and upholding the highest standards of care for our profession.
As academicians steeped in the difficulties and joys of practice and as wide-eyed medical students about to embark on a surgical career, we do not chastise those who complain, and in fact, we encourage others to join in with our chorus. After all, if we do not complain, who will?

DOI: 10.1097/01.PRS.0000089262.60250.B5

Navin Singh, M.D.

Plastic and Reconstructive Surgery

Johns Hopkins School of Medicine, and

R. Adams Cowley Shock Trauma Center

University of Maryland School of Medicine

Baltimore, $M d$.

Anand Mehra

Columbia College of Physicians and Surgeons

New York, N.Y.

Correspondence to Dr. Singh

Plastic and Reconstructive Surgery

Johns Hopkins School of Medicine

601 N. Caroline Street

McElderry 8130-C

Baltimore, Md. 21287-0981

nsingh@jhmi.edu

\section{REPLY}

Sir:

There is no doubt that we have not only the right but also the duty to voice our concerns to bring about a positive change for both the patients and ourselves. However, our duty extends with the responsibility to choose a venue and tone appropriate for our profession. Our profession is more than an occupation. It is a sacred relationship to our fellow man. From the child with a cleft lip to the woman with an aging face, we are charged to do whatever we can to make their lives better. It is a gift and a privilege, and we should not forget it.

As educators and leaders of the field, the efforts to bring about a positive change should be strong but carefully chosen. The labor should be targeted to those settings that will help accomplish our goals and should not serve to embitter residents and medical students.

The point of my original letter is best illustrated by the fact that a medical student coauthored the response. Someone who has embarked on a career in medicine with lofty goals should be wet with anticipation for the times ahead. The fact that medical students around the country who have yet to feel the joy of helping or healing are complaining only attests that we as a group have not fulfilled our duty to the next generation of doctors. As mentors for the neophytes, we should fuel the excitement and passion inherent to helping and healing and not the difficulties associated with our mission.

Again, improving our ability to fulfill our charge is ex- 
tremely important, as is improving our own lives. Choosing how and when we express our complaints requires thought and judgment.

Sean Boutros, M.D.

230 West 55 th St., \#5D

New York, N.Y. 10019

sean.boutros@med.nyu.edu

\section{RECONSTRUCTION OF THE COLUMELLA IN A PEDIATRIC PATIENT}

Sir:

Reconstruction of columellar defects continues to be a surgical challenge. Total loss of the columella and membranous septum poses even more difficulty than partial loss. In this letter, we report on a pediatric patient with a defect involving the entire columella along with the membranous septum and the caudal cartilaginous septum. Reconstruction of this defect was accomplished with the combination of a costal cartilage graft to support the nasal dorsum and an alar rim skin flap combined with a skin-cartilage composite graft to replace the absent columella.

A 3-year-old girl presented with a history of soft-tissue tumor involving the columella that had been present since birth. This tumor had been trimmed repeatedly by a family physician in another country. No further information was available regarding the nature of the original lesion. The patient's initial examination revealed total absence of the columella, the membranous septum, and the caudal cartilaginous septum. The nasal tip had lost projection and appeared collapsed. Heavy crusting interfered with air passage through the nose.

The surgical reconstruction was performed when the patient was 4.5 years old. A skin flap was elevated from the right alar rim based on the nasal tip (Fig. 1). Through the same incision, the dorsum was undermined to create a pocket for the costal cartilage graft. A 4-cm-long graft was harvested from the eighth rib with its perichondrium. A thin Kirschner wire

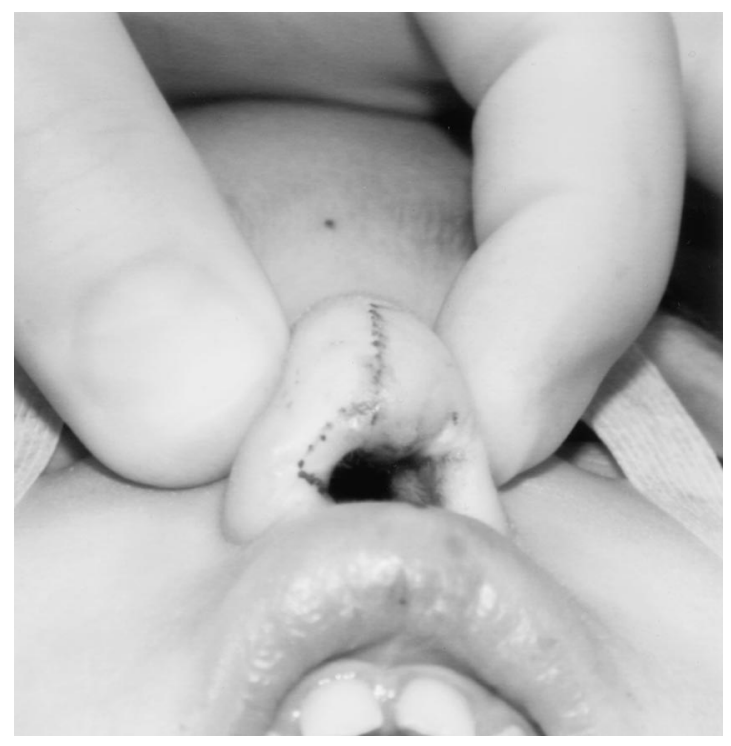

FIG. 1. Total columellar defect extending to the membranous septum and the caudal cartilaginous septum. Design of the medially based alar rim skin flap. was threaded through the graft to prevent future warping of the cartilage. The graft was carved around the Kirschner wire until the desired shape and length were achieved. After the graft was positioned in its pocket (Fig. 2), another Kirschner wire was introduced through the skin to fix the costal cartilage graft to the nasal bones. This maneuver reestablished the projection of the tip and relieved collapsing forces from the neocolumella.

The alar rim skin flap bridged the single nostril and was inset into the midline of the sill (Fig. 3). The blood supply to this flap was noticed to be especially rich, probably due to the loss of the columellar artery early in life. A skin-cartilage composite graft from the concha was shaped and inset to complete the reconstruction (Fig. 3). The alar rim skin flap served as the bed for the composite graft, whose "take" relied entirely on its vascularity.

A dorsal splint was applied for additional fixation of the

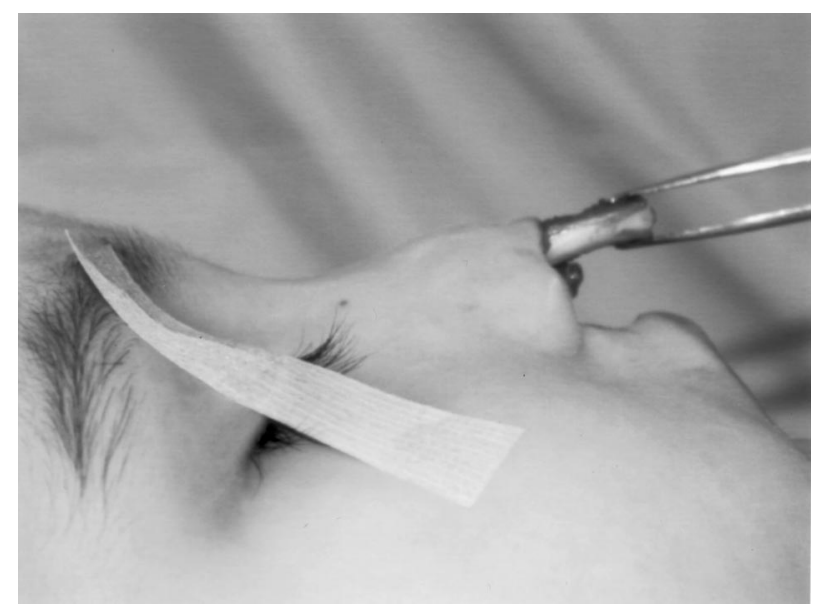

FIG. 2. Costal cartilage graft curved around Kirschner wire to support the nasal dorsum and the tip.

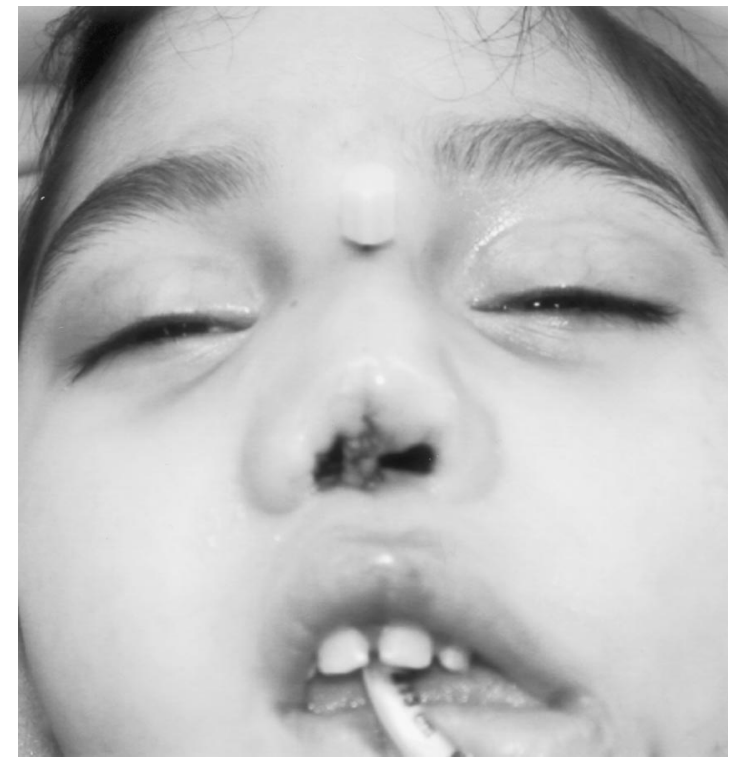

FIG. 3. Inset of the alar rim flap and the composite skincartilage graft. 


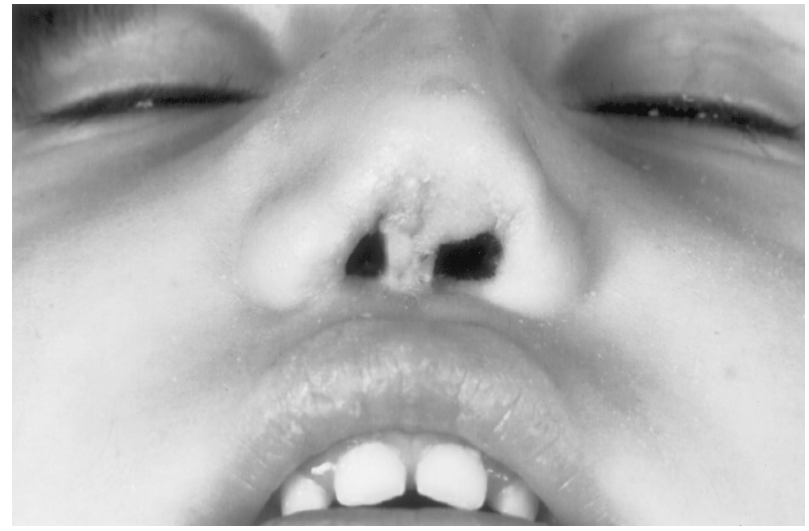

FIG. 4. Postoperative view.

costal cartilage graft. The percutaneous Kirschner wire was removed 3 weeks after the operation. The skin flap and the composite graft healed well, with a pleasing postoperative contour and color match (Fig. 4).

Among the nasal aesthetic subunits, the columella is the most difficult to reconstruct. Loss of the columella can be caused by malignancy, trauma, or infection, with resultant functional and aesthetic deformities that may be devastating for the patient. ${ }^{1}$ Nasolabial flaps (unilateral or bilateral),${ }^{2-5}$ forehead flaps, ${ }^{5-7}$ dorsal flaps based on the angular artery, ${ }^{1,8}$ bilateral alar flaps rotated from the tip, ${ }^{9,10}$ a forked flap from the upper lip, ${ }^{11}$ and microvascular free-tissue transfer have been described as possible surgical options. Most of these techniques require staged procedures for further contour adjustments and tip support. Composite grafts for columellar reconstruction have been described in partial columellar and alar rim defects, ${ }^{12}$ where sufficient vascular bed was available.

The technique described in this letter relies on several important principles in nasal reconstruction. The neocolumella is not to be expected to support the collapsed tip. This support should come from a different source, such as a stable dorsal cartilage graft, that will relieve pressure from the reconstructed columella and prevent its distortion.

The blood supply to the superiorly based alar rim skin flap is improved in the case of earlier loss of columellar artery, according to the principle of surgical delay. This flap proved to be reliable not only in terms of surviving but also in terms of supporting a composite graft.

The cartilage within the composite graft serves one purpose only: to shape the columella and improve its contour. This thin conchal cartilage probably will not provide substantial mechanical support for the tip, contrary to columellar struts used in rhinoplasty. It has been our practice to harvest the composite graft from the junction of the floor and the wall of the concha, as a relatively large graft can be recruited safely without creating a donor-site deformity.

The total columellar defect presents a unique problem that taxes the ingenuity of the plastic surgeon. Reconstruction of this defect with a combination of dorsal costal cartilage graft, alar rim skin flap, and composite auricular skin-cartilage graft is presented. We recommend adding this technique to the surgical armamentarium for reconstruction of these complex lesions.

DOI: 10.1097/01.PRS.0000089264.31445.E3
Alexander Margulis, M.D.

Bruce S. Bauer, M.D.

Hongshik Han, M.D.

Pravin K. Patel, M.D.

Division of Plastic Surgery

Shriners Hospital for Children, and

Children's Memorial Hospital

Chicago, Ill.

Correspondence to Dr. Margulis

2300 Children's Plaza, No. 93

Chicago, Ill. 60614

a-margulis@md.northwestern.edu

\section{REFERENCES}

1. Smith, V., and Papay, F. A. Surgical options in columellar reconstruction. Otolaryngol. Head Neck Surg. 120: 947, 1999.

2. Ozkus, I., Cek, D. I., and Ozcus, K. The use of bifid nasolabial flaps in reconstruction of the columella. Ann. Plast. Surg. 29: 461, 1992.

3. Yanai, A., Nagata, S., and Tanaka, H. Reconstruction of the columella with bilateral nasolabial flaps. Plast. Reconstr. Surg. 77: 129, 1986.

4. Dolan, R., and Arena, S. Reconstruction of the total columellar defect. Laryngoscope 105: 1141, 1995.

5. Burget, G. C., and Menick, F. J. Subtotal and total nasal reconstruction. In Aesthetic Reconstruction of the Nose. St. Louis: Mosby, 1994. Pp. 313-343.

6. Menick, F. J. Anatomic reconstruction of the nasal tip cartilages in secondary and reconstructive rhinoplasty. Plast. Reconstr. Surg. 104: 2187, 1999.

7. Menick, F. J. A 10-year experience in nasal reconstruction with the three-stage forehead flap. Plast. Reconstr. Surg. 109: 1839, 2002.

8. Conley, J., Sachs, M. E., and Donovan, D. Mini alar myocutaneous flaps for nasolabial-columella reconstruction. Otolaryngol. Head Neck Surg. 91: 380, 1983.

9. Jackson, I. T. Local Flaps in Head and Neck Reconstruction. St. Louis: Mosby, 1985. Pp. 1338-1340.

10. Millard, D. R. A Rhinoplasty Tetralogy. Boston: Little, Brown, 1996. Pp. 334-423.

11. Pincus, R. L., and Bukachevsky, R. P. Medially based horizontal nasolabial flaps for reconstruction of columellar defects. Arch. Otolaryngol. Head Neck Surg. 116: 973, 1990.

12. Cho, B. C., Park, J. W., and Baik, B. S. Correction of severe secondary cleft lip nasal deformity using a composite graft: Current approach and review. Ann. Plast. Surg. 48: 131, 2002.

\section{CHIN AUGMENTATION WITH CONGHAL CARTILAGE}

Sir:

We have read the article "Chin Augmentation with Conchal Cartilage” by F. Viterbo (Plast. Reconstr. Surg. 111: 899, 2003), and in our view and given our clinical and experimental experience, there are some points that should be illuminated.

The author performed conchal grafts to the chin of patients who requested mentoplasty by itself or combined with rhinoplasty, rhytidoplasty, or submental lipoplasty. The con- 
chal cartilage was harvested subperichondrally through a posterior 3 -cm incision. The specimen measured $3 \times 1 \mathrm{~cm}$, which was sufficient to project the chin 2 to $3 \mathrm{~mm}$. For 4 to $5 \mathrm{~mm}$ of projection, both cartilages were used. The graft was positioned under the periosteum and was held with two 5-0 nylon sutures. In these cases, the conchal cartilage graft was a suitable option for chin augmentations up to $5 \mathrm{~mm}$.

Mild to moderate microgenic patients would not need osteotomies, and augmentation mentoplasty could be enough to balance the facial profile. ${ }^{1,2}$ The use of autologous grafts might be more appropriate in many circumstances, but resorption is a potential problem with all biologic grafts. Adams ${ }^{3}$ claimed that Silastic (either rubber-filled or gelfilled) prostheses (Dow Corning, Midland, Mich.) produced the most pleasing and long-lasting results for the chin and were superior to biological materials. The biological grafts possess the same risk of infection in the early postoperative period as the alloplastic implants, but in long-term follow-up, the integration and the increased vascularity of the biological grafts prevent infection. ${ }^{4-6}$ This integration process could culminate in increased resorption. ${ }^{7}$ The surgeon should choose the best alternative for chin augmentation according to the patient's demands. We prefer to use autologous grafts for augmentation according to the severity of the microgenia. The bone grafts harvested from the iliac crest or rib reveal permanent results, especially in severe microgenia. The replacement of the bone graft subperiosteally helps in the integration of the graft to the recipient area. All other grafts, including cartilage, dermofat, or adipose, should be placed subdermally, over the mental muscles, instead of subperiosteally. According to our experience, the pressure caused by the inelastic property of the periosteum increases the resorption of tissues except in the case of bone. The author indicated good results at 4 years of follow-up and explained the final outcome as the ossification of the cartilage. Could this ossification be new bone formation under the periosteum during cartilage resorption?

In 1958, Aufricht ${ }^{1}$ described the use of the nasal hump that was removed during rhinoplasty and placed supraperiosteally. In his series of 700 cases, resorption was not encountered, as supported by plain roentgenograms. Mottura ${ }^{8}$ also used the osteocartilaginous hump harvested from the rhinoplasty for augmentation of the chin, and the late results were indicated by tridimensional computed tomography, which showed osteointegration with the mandibular bone and no resorption of the grafts or alteration of the structure of the bone. The main deficient tissue in microgenia is the bone; so in our view, autologous tissues, including bone, should be used in augmentation. Conchal cartilage grafts have been used in nasal augmentation in rhinoplasty operations. ${ }^{9,10}$ The two dimensions of the conchal cartilage grafts enable good sources in augmentation, but the thin structure could not be sufficient in prominence. The author presents chin augmentations up to $5 \mathrm{~mm}$ with a follow-up of 4 years. Could the thin cartilage grafts supply a prominence of $5 \mathrm{~mm}$, and could they resist resorption under the periosteum for a long time? Would a maximum of $5 \mathrm{~mm}$ of prominence be acceptable to both the patient and the surgeon?

Conchal cartilage grafts are complementary sources of grafts not only in aesthetic surgery but also in reconstructive surgery. ${ }^{11,12}$ Use of these cartilage grafts is a convenient method for chin augmentation but only in selected and suitable patients. The preoperative planning should be meticulous, and the resorption of these grafts should not be forgotten.

DOI: 10.1097/01.PRS.0000089265.01498.2E

\author{
A. Cağrn Uysal, M.D. \\ M. Sahin Alagöz, M.D. \\ R. Erkin Ünlü, M.D. \\ Ömer Şensöz, M.D. \\ Ankara, Turkey \\ Correspondence to Dr. Uysal \\ Doruk Sitesi No. 13 \\ 06530 Cayyolu \\ Ankara, Turkey \\ cagriuysal@hotmail.com
}

Department of Plastic and Reconstructive Surgery Ankara Numune Training and Research Hospital

\section{REFERENCES}

1. Aufricht, G. Combined plastic surgery of the nose and chin. Am. J. Surg. 95: 231, 1958.

2. Gibson, F. B., and Calhoun, K. H. Chin position in profile analysis: Comparison of techniques and introduction of the lower facial triangle. Arch. Otolaryngol. Head Neck Surg. 118: 273, 1992.

3. Adams, J. S. Grafts and implants in nasal and chin augmentation: A rational approach to material selection. Otolaryngol. Clin. North Am. 20: 913, 1987.

4. Joos, U., and Kleinheinz, J. Reconstruction of the severely resorbed (class VI) jaws: Routine or exception? J. Craniomaxillofac. Surg. 28: 1, 2000.

5. Newman, J., Dolsky, R. L., and Mai, S. T. Submental liposuction extraction with hard chin augmentation. Arch. Otolaryngol. 110: 454, 1984.

6. Goldemberg, B. Dermofat graft for profileplasty. Aesthetic Plast. Surg. 10: 41, 1986.

7. Breitbart, A. S., and Ablaza, V. J. Implant materials. In S. J. Aston, R. W. Beasley, and C. H. Thorne (Eds.), Grabb and Smith's Plastic Surgery, 5th Ed. Philadelphia: Lippincott-Raven, 1997. P. 39.

8. Mottura, A. A. Chin augmentation with nasal osteocartilaginous graft. Plast. Reconstr. Surg. 109: 783, 2002.

9. Muenker, R. The bilateral conchal cartilage graft: A new technique in augmentation rhinoplasty. Aesthetic Plast. Surg. 8: 37, 1984.

10. Regnault, P. Nasal augmentation in the problem nose. Aesthetic Plast. Surg. 11: 1, 1987.

11. Siemian, W. R., and Samiian, M. R. Malar augmentation using autogenous composite conchal cartilage and temporalis fascia. Plast. Reconstr. Surg. 82: 395, 1988.

12. Stark, R. B., and Frileck, S. P. Conchal cartilage grafts in augmentation rhinoplasty and orbital floor fracture. Plast. Reconstr. Surg. 43: 591, 1969.

\section{REPLY}

Sir:

I read attentively the interesting observations made by Drs. Uysal et al. concerning my article, "Chin Augmentation with Conchal Cartilage” (Plast. Reconstr. Surg. 111: 899, 2003). I would like to take this opportunity to clarify this method in more detail.

Although the cartilage is not very thick, its undulations allow a 2-mm to 3-mm projection and even a 4-mm to 5-mm projection when two cartilage pieces are used.

When suturing both cartilages, it is important to place them so that the undulations are not superposed, because this 
leads to a smaller projection. On the contrary, one should try to add the undulations of one piece of cartilage to the undulations of the other.

In cases where projections greater than $5 \mathrm{~mm}$ are needed, we have opted for a basilar osteotomy of the mandible with advancement or implants of alloplastic materials such as porous polyethylene.

The ossification seen on a radiograph in one of our cases can perfectly explain the lack of absorption of these grafts in all our series. We believe that the subperiosteal placing of such grafts should be done precisely to allow this ossification. We believe that if the implants were placed subcutaneously, they would show an undesired mobility. We do not believe that this cartilage undergoes absorption to subsequently give rise to this ossification process.

In all cases of this series, both the patient and the surgeon were satisfied with the results. The meticulous selection of cases for this method should obviously be emphasized.

Fausto Viterbo, M.D., Ph.D.

Discipline of Plastic Surgery

Faculdade de Medicina

Universidade Estadual Paulista

Rua Magnólia 265

Botucatu SP 18607-670, Brazil

viterbo@fmb.unesp.br

\section{BUTTOGK IMPLANTS FOR MALE CHEST ENHANGEMENT}

Sir:

Little attention has been paid among plastic surgeons to male chest enhancement. Even though this procedure is rare compared with other body implant operations, more men are asking for and even undertaking this operation.

Aiache $^{1}$ was one of the first surgeons to describe the technique, and recently Horn ${ }^{2}$ reported his results in 12 patients. The surgical technique is well explained in these articles.

Not many manufacturers produce and distribute pectoral implants. Silimed Corporation (Dallas, Texas) provides these implants in the United States, but in Spain (and, I presume, in all of Europe), anatomical pectoral implants as described are not found.

We are using buttock implants (Polytech-Silimed Europe GmbH, Dieburg, Germany) for pectoral enhancement. The Otero and Vergara implants are almond-shaped, properly oriented (Fig. 1), and fit very well in the pocket. Otero implants are smooth; Vergara implants are textured. I have used both types, and the selection depends on the patient's wishes

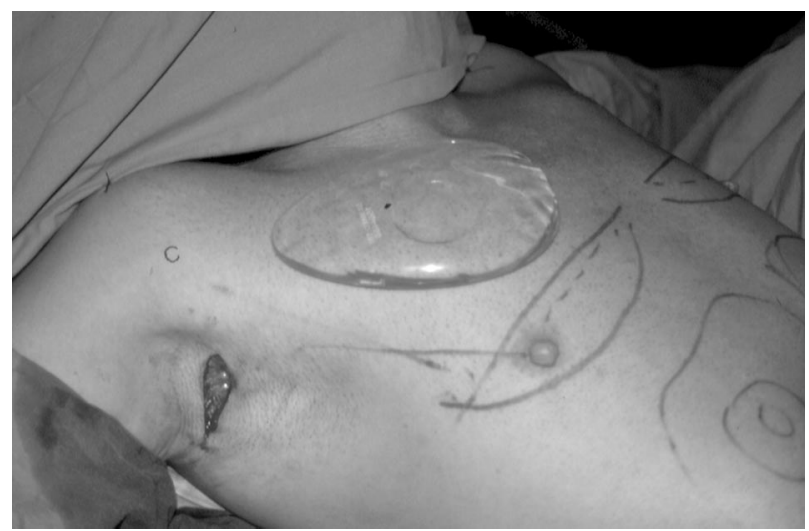

FIG. 1. Otero's implant for male chest augmentation. and body frame. The most common volume is $180 \mathrm{cc}$, and it is only available in the Otero implants. In Vergara implants, volume starts at $240 \mathrm{cc}$. The advantage of textured over smooth implants is that they have $1 \mathrm{~cm}$ more of projection. If the chest is narrow or if lateral herniation or upward displacement of the implant is a concern, Vergara implants are more suitable than Otero implants for giving more projection with the same width and length.

DOI: 10.1097/01.PRS.0000089267.80808.B3

Jesús Benito-Ruiz, M.D.

Plastic and Aesthetic Surgery c/ Muntaner $2602^{\circ} 3^{a}$ 08021 Barcelona, Spain drbenito@cirugia-estetica.com

\section{REFERENCES}

1. Aiache, A. E. Male chest correction: Pectoral implants and gynecomastia. Clin. Plast. Surg. 18: 823, 1991.

2. Horn, G. A new concept in male chest reshaping: Anatomical pectoral implants and liposculpture. Aesthetic Plast. Surg. 26: 23, 2002.

\section{ABOUT IMAGES WITH BREAST IMPLANTS AND GALACTOCELE}

Sir:

I read the communication by Dr. Abenavoli et al. published in the January of 2003 issue of the Journal entitled "Breast Implant Evaluation: Pitfall of Magnetic Resonance Imaging” (Plast. Reconstr. Surg. 111: 507, 2003), and I would like to share my experience with image diagnosis of fluid collections related to breast implants, focusing on seroma.

Late appearance of seroma is a frequent complication with breast implants, and it is very common for it to be misdiagnosed or to appear without clinical symptoms or signs. Surgeons often find some amount of fluid when changing prostheses in the space between the implant and the capsule. Seroma, a collection of fluid or protein-like fluid, is a condition that may appear in an early or late postoperative course of breast implantation. Inflammatory cells release chemical mediators such as histamine and several prostaglandins, which results in an increase of interstitial fluid. ${ }^{1}$ Immediate and late seroma are different. Immediate seroma is an inflammatory condition that involves almost all the implant's insertion for the first 2 weeks. The amount of fluid may be scarce, but in all the sonograms performed at that time, a regular seroma can be observed. Late seroma has another etiology. The rubber friction of a textured implant causes the capsule to split, leaving two envelopes: the inner capsule adheres to the implant and the outer capsule is smoothwalled, as usually found with slick silicone implants attached to the muscle or mammary gland. The seroma is found in the space between the two capsules. ${ }^{2}$ Excessive upper limb motion, usually in submuscular implantation, causes this friction. The first and the best diagnostic method is breast ultrasonography. What are the pitfalls of this procedure? This is an operator-dependent procedure. This is a study that must be performed by a radiologist experienced in breast imaging. Ultrasonography is most accurate when image interpretation takes place at the time of the study. ${ }^{3}$ Real-time ultrasonographic images are more useful than hard-copy images. A breast cyst can be misdiagnosed as a cross-section of a wrinkled implant. The sonogram is reliable and less expensive ${ }^{3}$ 
with an experienced observer. The breast sonogram is my first choice in diagnosis of breast implant rupture, too. The level of confidence is 87 percent. $^{4}$

In seroma treatment, I first attempt to control the situation without an operation by focusing on eliminating the possible origin of the complication. If I have any doubt concerning the collection, I may do a needle aspiration under ultrasound assistance. The treatment I prefer is to make a compression bandage of the breast and an immobilization cast of the upper limb $b^{1}$ to prevent any motion (10 to 15 days). As far as medication is concerned, a dual-acting (fast and slow release) corticosteroid and antibiotic therapy (ciprofloxacin, $1 \mathrm{~g}$ per day for 1 week) are indicated. Avoiding motion in the area is the way to ensure that both capsules may fuse again. I use the surgical approach for cases of relapsing seroma but not as a first-choice treatment.

In their brief communication, Abenavoli et al. report a very interesting case. Galactocele is a rare condition inside the mammary gland that is associated with sudden breast-feeding suppression within the few months preceding the appearance of a clinical mass. It may be detected by ultrasonography, ${ }^{5}$ but it is difficult to differentiate from a seroma outside the gland with magnetic resonance imaging or any radiological tool. Both give the image of a collection but not the characteristics of the effusion (very similar amount of protein content), which must be confirmed by needle aspiration under echographic control. It is not well established in the medical literature that a milky collection outside the mammary gland can be considered a galactocele. It is usually situated in the central breast area with its own cystic wall. To confirm the diagnosis, a careful pathological study ${ }^{6}$ is necessary to determine whether the growth is really a cyst or a dilated duct and to identify the nature of the epithelial lining. There are reports of galactocele in infants. ${ }^{7}$ This case and other cases that have been described ${ }^{8}$ are outside the mammary gland, and the cystic wall is the capsule of the implant. Although Abenavoli et al. give no information about the type of implant, the subpectoral placement and the magnetic resonance image of a bilateral collection raise the possibility of a late seroma (more frequent with textured implants and with protein content) tinged with milk.

With regard to magnetic resonance in breast implant imaging, it is difficult to diagnose any characteristics of fluid collection. The only possible diagnosis is just fluid collection, and the surgeon should decide what to do, matching the images and the clinical case. Magnetic resonance imaging is a diagnostic method that has high sensitivity but low specificity. ${ }^{9}$ This difference between sensitivity and specificity means that although this is a photographic image (which does not rely on the observer to get the image, as with ultrasound), it requires expertise in reading images. Ikeda et al. ${ }^{9}$ report that magnetic resonance imaging sensitivity was 100 percent and specificity was 63 percent in the diagnosis of breast implant rupture. How many cases have been misdiagnosed due to magnetic resonance imaging as breast implant rupture because of overinterpreting findings within the implant instead of interpreting contour abnormalities?

Regarding the relationship between galactocele and high prolactin levels, it is noticeable that many patients who undergo breast augmentation have high prolactin levels, and galactocele is a rare condition. ${ }^{8}$ Also, it is true that galactorrhea is a very common finding and is associated with high levels of prolactin. Vincent ${ }^{10}$ studied preoperative prolactin in breast augmentation and found high prolactin levels in his series and no galactocele in more than 2 years of postoper- ative control. The relationship between high prolactin levels and galactocele needs further study to be confirmed.

Diagnostic imaging methods (ultrasonography, mammography, or magnetic resonance imaging) require careful reading by an expert in breast implants, who will match the findings with the patient's clinical record to obtain an accurate diagnosis.

DOI: 10.1097/01.PRS.0000089268.74391.51

Oscar A. Zimman, M.D., Ph.D.
Department of Surgery
Division of Plastic Surgery
Hospital de Clínicas "José de San Martín"
School of Medicine
University of Buenos Aires
Av. Córdoba 2351
Buenos Aires C1120AAF, Argentina
ozimman@fmed.uba.ar

\section{REFERENCES}

1. Knight, C. D., Jr., Griffen, D., and Knight, C. D. Prevention of seroma in mastectomy wounds: The effect of shoulder immobilization. Arch. Surg. 130: 99, 1995.

2. Robinson, H. N. Double capsule formation with textured silicone implants. In Proceedings of the 25th Annual Meeting of the Aesthetic Plastic Surgery Society, Los Angeles, Calif., May 3-8, 1992.

3. Chung, K. C., Wilkins, E. G., Beil, R. J., Jr., et al. Diagnosis of silicone gel breast implant rupture by ultrasonography. Plast. Reconstr. Surg. 97: 104, 1996.

4. Liston, J. C., Malata, C. M., Varma, S., Scott, M., and Sharpe, D. T. The role of ultrasound imaging in the diagnosis of breast implant rupture: A prospective study. Br. J. Plast. Surg. 47: 477, 1994.

5. Sawhney, S., Petkovska, L., Ramadan, S., Al-Muhtaseb, S., Jain, R., and Sheikh, M. Sonographic appearance of galactocele. J. Clin. Ultrasound 30: 18, 2002.

6. Azzopardi, J. Problems in Breast Pathology. Philadelphia: Saunders, 1979. Pp. 68-70.

7. Saray, A., Aydin, O., Ozer, C., and Tamer, L. Galactocele: A rare cause of breast enlargement in an infant. Plast. Reconstr. Surg. 108: 972, 2001.

8. Deloach, E. D., Lord, S. A., and Ruf, L. E. Unilateral galactocele following augmentation mammaplasty. Ann. Plast. Surg. 33: 68, 1994.

9. Ikeda, D. M., Borofsky, H. B., Herfkens, R. J., SawyerGlover, A. M., Birdwell, R. L., and Glover, G. H. Silicone breast implant rupture: Pitfalls of magnetic resonance imaging and relative efficacies of magnetic resonance, mammography and ultrasound. Plast. Reconstr. Surg. 104: 2054, 1999

10. Vincent, N. Prolactin levels related to the fibrous envelope around mammary implants (in Spanish). Presented at the Sociedad de Cirugía Plástica de Buenos Aires, Buenos Aires, Argentina, December 4, 2000.

\section{REPLY}

Sir:

First, I would like to thank Dr. Zimman for the attention he gave to our letter ${ }^{1}$; however, I wish to make some elements clear that I think are useful to point out. Utilization of the ultrasound method in studying the breast even after an aug- 
mentation mastoplasty is well established, as this technique is not invasive, is rapidly performed with a good rate of reliability, and is not so expensive. Yet, when an alteration of the mammary prothesis or another abnormal condition of the breast containing the prothesis is suspected, the degree of reliability of the ultrasound method is no longer satisfactory; thus, it is necessary to resort to a nuclear magnetic resonance examination, which guarantees greater reliability. A nuclear magnetic resonance examination is, in fact, a useful method that, though limited, provides greater reliability when compared with other methods. Moreover, a further guarantee is the fact that the operator's skill is not directly proportional to the method's reliability, which is not the case in an ultrasound examination.

The purpose of our letter, therefore, was exactly that of highlighting a further possible limit of this methodology. The case proposed by us was that of a patient with submuscularly placed, textured mammary protheses who, a few months after the operation, suddenly had an effusion around one of the protheses that was diagnosed at the nuclear magnetic resonance examination as a seroma but in actuality was discovered to be a milk effusion after surgical exploration. This should be remembered and suspected in cases demonstrating similar characteristics.

Regarding the method proposed by Dr. Zimman of using needle aspiration under ultrasound control for the diagnosis, due to its invasiveness and danger, I firmly believe it should be reserved for special cases and only applied by expert medical personnel.

Fabio Massimo Abenavoli, M.D. Via Savoia 72 Rome 00198, Italy

\section{REFERENCE}

1. Abenavoli, F. M., Corelli, R., and Giordano, L. Breast implant evaluation: Pitfall of magnetic resonance imaging. Plast. Reconstr. Surg. 111: 507, 2003.

\section{THE ELECTROCARDIOGRAPHY DOT AS A PREOPERATIVE MARKER FOR NIPPLE-AREOLA COMPLEX RECONSTRUCTION}

Sir:

We read with interest the letter by Mahajan et al. entitled "The Electrocardiography Dot as a Preoperative Marker for Nipple-Areola Complex Reconstruction" (Plast. Reconstr. Surg. 111: 955, 2003). We congratulate the authors on drawing attention to this use of the electrocardiography dot, which we, too, have found extremely useful in determining the ideal position for the future nipple-areola complex. We would like to point out, however, that despite the authors stating that this technique has not been previously published, we reported this use along with our technique for nipple-areola reconstruction in $1997 .^{1}$

According to our experience, the main advantages of the use of the electrocardiography dot are as follows. First, the future position of the nipple-areola complex can be visualized in three dimensions, meaning that symmetry can be checked from the sides as well as from the front. Second, the patient is actively involved in the decision-making process, ensuring long-term patient satisfaction.

DOI: 10.1097/01.PRS.0000089270.22537.F1

\author{
G. J. Zambacos, M.D. \\ A. D. Mandrekas, M.D. \\ Artion Plastic Surgery Center \\ Athens, Greece \\ Correspondence to Dr. Zambacos \\ Artion Plastic Surgery Center \\ 11 D. Vassiliou Street \\ N. Psyhiko \\ Athens 15451, Greece \\ gzambacos@artion-plasticsurgery.com
}

\section{REFERENCE}

1. Mandrekas, A. D., and Zambacos, G. J. Modified quadrapod flap. Ann. Plast. Surg. 38: 195, 1997.

\section{MEASURING OUTCOMES IN AESTHETIC SURGERY}

Sir:

"Measuring Outcomes in Aesthetic Surgery: A Comprehensive Review of the Literature" by Ching et al. (Plast. Reconstr. Surg. 111: 469, 2003) is a provocative article exploring a topic important to all plastic surgeons. The question is not whether to evaluate our results but how ${ }^{1,2}$ I offer the following views with the hope of expanding our perspective on the subject.

The authors have identified body image and quality-of-life measures to be of greatest use in determining aesthetic surgery outcomes. These measurements are subjective, based on the objective observation of the cosmetic surgical result. An objective evaluation is essential, because the quality of the result will profoundly influence the subjective impression the patient derives.

The authors state, "the creation of beauty is subjective and eludes clear definition." True, but understanding beauty is not beyond our capacity. When toddlers are shown photographs of an attractive face and a less attractive face, they spend more time looking at the attractive face. Young students rate better-looking teachers as better teachers. Goodlooking people are perceived as healthier than their homely counterparts. We have an innate appreciation for beauty in the human form.

It is true that neoclassical Greek and present-day ideals do not show a correlation. It shows that our perceptions of beauty are colored by environmental influences, cultural transmission, and social biases. Consider how the media influence styles, trends, and promote fads.

Beauty is the subjective impression of an objective object. In the human form, beauty requires symmetry (an objective observation) of average parts (that which we consider normal, affected by environmental and cultural differences and biases) and harmony (that the parts fit together in an expected way). This "normal" framework is necessary, as it defines our expectations of what is beautiful in the human form.

The authors contend, "There is likely to be little consensus between surgeons in the types of measurements that are considered important in grading cosmetic surgery results." But plastic surgeons agree on the principles that form the foundation of our specialty. This provides agreements upon 
which further consensus can be built. We can all agree that scar is not a desirable attribute of cosmetic surgery. We always aim to diminish scar. We also agree that symmetry of paired body parts and of the two halves of single parts is essential for beauty. Has a patient ever requested asymmetric breasts? Is a malpositioned umbilicus or startled brow desirable? Do we not aim to avoid tension lines or distorted earlobes when performing a face lift? Do we not strive for smooth curvilinear lines to avoid contour deformities such as submental puckering after a face lift or unsightly bulges and depressions after liposuction? We all strive to avoid malposition, distortion, asymmetry, contour deformity, and scar. These are objectively verifiable deviations from an ideal result I previously described. 1,3 "Furthermore, these methods are likely to be expensive and laborious, requiring special equipment to implement," the authors contend. On the contrary, the results are obtainable at no cost, by simple observation requiring, at most, a ruler or tape measure.

I take issue with the authors who classified my grading system as subjective. The dictionary defines subjective as "existing in the mind" and "characteristic as perceived as opposed to reality as it is in itself." ${ }^{, 5}$ It is "peculiar to a particular individual modified by individual biases and limitations." Objective is "something real and observable." As all flaw categories in my grading system are real and observable, they are objective.

I found, using my grading system, that a flawless result always created happy patients as long as I respected their desires in shape and size. I suggest that patient dissatisfaction is due to a compromised result rather than "unfavorable interpersonal relationships between the patient and doctor." Patients see flaws and they do not like them; this leads to unhappiness, created by the flaws. The doctor's refusal to "see" the apparent flaw aggravates the problem and may lead to "unfavorable interpersonal relationships." Open, honest communication leads to honest answers, and I do not believe there is a "high likelihood of bias from patients reporting their satisfaction to their surgeons." I find patients to be competent in identifying "flaws," and the surgeon's objective verification and correction leads to satisfied patients.

Taking the above into consideration, I expect that the authors' concepts will provide us with a better understanding of our patients. I hope they take my comments in a positive vein and use them to carry their ideas to fruition.

DOI: 10.1097/01.PRS.0000089271.96407.D5

Eugene J. Strasser, M.D.

1505 University Drive

Coral Springs, Fla. 33071

\section{REFERENCES}

1. Strasser, E. An objective grading system for the evaluation of cosmetic surgical results. Plast. Reconstr. Surg. 104: 2282, 1999.

2. Losken, A., and Bostwick, J. Discussion on evaluation of results in aesthetic plastic surgery: Preliminary observations on mammaplasty. Plast. Reconstr. Surg. 106: 1636, 2000.

3. Strasser, E. Application of an objective grading system for the evaluation of cosmetic surgical results. Plast. Reconstr. Surg. 109: 1733, 2002.

4. Barnhart, C. L., and Barnhart, R. K. (Eds.). The World Book Dictionary. Chicago: World Book-Childcraft International, 1980.

5. Grove, P. B. (Ed.). Webster's Third New International Dic- tionary of the English Language Unabridged: With Seven Language Dictionaries. Chicago: Encyclopedia Britannica, 1986. Pp. 155-156, 2275-2276.

\section{REPLY}

Sir:

We thank Dr. Strasser for his concerns regarding our review on the assessment of cosmetic surgical outcomes (Measuring Outcomes in Cosmetic Surgery: A Comprehensive Review of the Literature. Plast. Reconstr. Surg. 111: 469, 2003). Dr. Strasser is clearly an experienced surgeon who has developed an elegant grading system for evaluating surgical results. ${ }^{1}$ However, we maintain our view that his grading system, in its present form, is not sufficient for measuring outcomes in cosmetic surgery.

In our study, we conducted a comprehensive review of the entire cosmetic surgery literature to identify the methods that have been used to measure aesthetic surgical outcomes. ${ }^{2} \mathrm{We}$ subjected these instruments to a systematic evaluation by an established method to assess their value, ${ }^{3}$ including their reliability and validity. In brief, validity refers to the question: "Does this instrument measure the health state in question?" Reliability refers to whether an instrument consistently measures the same result upon repeated measurements made by a single assessor or multiple individuals.

Dr. Strasser's malposition, distortion, asymmetry, contour deformity, and scar, or MDACS, scale measures the severity of flaws arising from cosmetic surgical interventions. Specifically, the qualities of malposition, distortion, asymmetry, contour deformity, and scarring are graded on an ordinal scale of 0 to 15 . Although these qualities are clinically important, we question their exclusive use in the assessment of patient outcomes.

Outcomes research refers to a branch of medical science that aims to study the effects of medical interventions, taking into account patients' experiences, preferences, and values. ${ }^{4}$ This is in contrast to traditional methods, such as the MDACS scale, that center on the perspective of the surgeon in evaluating surgical results.

After our review, we concluded that the assessment of outcome from a patient's perspective is the most pertinent perspective in aesthetic surgery, as the satisfaction of the patient is ultimately the true measure of success.

In terms of validity, we question whether the MDACS scale can accurately measure the outcome of interest. Although we agree with Dr. Strasser that "the concept of beauty is subjective and eludes a clear definition,"1 we do not believe that the measurement of flaws alone should be the basis on which we assess relevant outcomes. In our experience, malposition, distortion, asymmetry, contour deformity, and poor scarring do not occur in most patients. How, then, can we measure and compare outcomes in patients when these negative qualities are largely absent?

Another difference in our opinions arises from the classification of the MDACS scale as subjective. As Dr. Strasser has previously stated, "One surgeon's 'good' result may be perceived by another surgeon in a totally different light." Consequently, it remains entirely possible to us that one surgeon's symmetry could be another's asymmetry. Moreover, a patient's perception of these varied flaws could easily be entirely different from a surgeon's perception. All of these qualities are in accordance with our definition of subjective, which is 
"modified or affected by personal views, experience, or background." 5

Although Dr. Strasser claims that these results may be "obtainable at no cost, by simple observation requiring, at most, a ruler or tape measure," it is unclear what exactly is being measured. While these flaw qualities could be "real and observable," we conclude that the grading of these flaws is clearly subjective as opposed to objective, which we define as: "of or having to do with a material object as distinguished from a mental concept, idea or belief" ${ }^{\prime 6}$ and "expressing or dealing with facts or conditions as perceived without distortion by personal feelings, prejudices, or interpretations."

Some of these problems could be addressed by refinements of the MDACS scale to define the grading of each of the characteristics so that easily reproducible measurements could be made (e.g., malposition and asymmetry). However, this may prove to be difficult in categories of contour deformity, distortion, and scar. In conjunction with an assessment of validity as previously mentioned, an analysis of the reliability of the instrument would be crucial. Scores need to be reproducible both by individual surgeons examining the same result on multiple occasions (intrarater reliability) and multiple surgeons examining the same patient (interrater reliability). Furthermore, the scale would benefit from a formal study to examine the correlation of scores to patient satisfaction.

We have no doubt that the scale devised by Dr. Strasser may be a clinically useful tool to document surgical results. The qualities measured by the scale are relevant and, with modification, could become an important component of a multimodal outcome assessment, which would include patient satisfaction and quality-of-life measures. This may allow for the assessment of true outcomes in cosmetic surgery that will allow our specialty to compare results of specific patient groups and quantify the improvement in quality of life we offer our patients.

The achievement of these goals would be a notable advance in the field of cosmetic surgery. Finally, we could begin to compare surgical interventions to determine which are the most beneficial. The quantification of the improvement in quality of life would provide the ability to demonstrate to our other surgical colleagues and to health organizations the remarkable benefits we can offer through cosmetic surgery.

We believe that only through the assessment of outcomes using valid and reliable instruments can our field of aesthetic surgery progress. We encourage Dr. Strasser to refine his grading system so that we can work together to achieve this goal.

Shim Ching, M.D., M.Sc.

Achilleas Thoma, M.D., M.Sc.

Randi E. McCabe, Ph.D., C. Psych.

Martin M. Antony, Ph.D., C. Psych.

Division of Plastic Surgery

Department of Surgery, and

Anxiety Treatment and Research Centre

St. Joseph's Healthcare Hamilton, and

Department of Psychiatry and Behavioural Neurosciences

McMaster University

Hamilton, Ontario, Canada

Correspondence to Dr. Thoma

206 James Street South, Suite 101

Hamilton, Ontario, L8P $3 A 9$

Canada

athoma@mcmaster.ca

\section{REFERENCES}

1. Strasser, E. An objective grading system for the evaluation of cosmetic surgical results. Plast. Reconstr. Surg. 104: 2282, 1999.

2. Ching, S., Thoma, A., McCabe, R. E., and Antony, M. Measuring outcomes in cosmetic surgery: A comprehensive review of the literature. Plast. Reconstr. Surg. 111: 469, 2003.

3. McDowell, I., and Newell, C. Measuring Health: A Guide to Rating Scales and Questionnaires. New York: Oxford University Press, 1996.

4. Clancy, C. M., and Eisenberg, J. M. Outcomes research: Measuring the end results of health care. Science 282: $245,1998$.

5. Strasser, E. Application of an objective grading system for the evaluation of cosmetic surgical results. Plast. Reconstr. Surg. 109: 1733, 2002.

6. Boyer, M., Ellis, K., Harris, D. R., and Soukhanov, A. H. (Eds.). The American Heritage Dictionary. Boston: Houghton Mifflin, 1986. P. 677.

7. Merriam-Webster, Incorporated. The Merriam-Webster Online Dictionary. Available at: http://www.mw.com/home.htm. Accessed April 2003.

\section{A SIMPLE METHOD TO STABILIZE THE PENIS DURING OPERATION}

Sir:

One of the reasons for technical difficulty in performing operations on the penis is that it can be too small, too mobile, or too flaccid to be manipulated and fixed appropriately during the operation. Our method to fix the penis during phalloplasty is presented.

Several sutures are placed around the coronary sulcus. These sutures are tied together, and the knot is connected with rubber bands. The other end of the rubber bands is fixed onto the sterilized handle of the surgical light with adhesive tape. By moving the surgical light back and forth or left and right, the penis can be moved and fixed appropriately, presenting the necessary aspect of the penis to the surgeon. Appropriate tension given by the rubber bands also enables the surgeon to determine whether curvature of the penis has been adequately corrected. Sutures may be left in place after the operation and used as the fixation method to maintain the penis in a straight and upright position.

DOI: 10.1097/01.PRS.0000089273.63724.F8

Takao Harashina, M.D.

Yukako Ohtsuki, M.D.

Department of Plastic and Reconstructive Surgery

Saitama Medical Center

Saitama Medical School

Correspondence to Dr. Harashina

Department of Plastic and Reconstructive Surgery

Saitama Medical Center

Saitama Medical School

Kamoda, Kawagoe

Saitama 350-8550, Japan

harasina@saitama-med.ac.jp 


\section{COMPARTMENT SYNDROME AFTER SUBSTITUTION VAGINOPLASTY: AN ONEROUS MEDICAL COMPLICATION}

Sir:

A 16-year-old female patient with a diagnosis of 5 - $\alpha$-reductase deficiency was seen in the pediatric surgery ward during consultations for complaints of erythema, tenderness, and edema in her left leg. She had been seen and diagnosed by pediatric surgeons as having male pseudohermaphroditism, and previous serial operations had been carried out. At the most recent operation, substitution vaginoplasty using a colonic segment was performed. She declared that her complaints emerged immediately on the same day as the operation. The physical examination revealed increased diameter of the left leg and a hard, warm, and tender posterior compartment. The arterial pulses of the lower extremities were patent. She was then intimately followed with the likely diagnosis of deep venous thrombosis or compartment syndrome. A Doppler ultrasonogram of the lower extremity was unremarkable. Elevation and cold application did help a little that night, but with the persistent clinical findings, the patient was taken to the operating room in the morning with the diagnosis of compartment syndrome. Fasciotomies of the leg were performed using one medial incision and one lateral incision, without fibulectomy. After an uneventful 1-week hospital stay, the fasciotomies were closed in a stepwise fashion (first the lateral fasciotomy followed 1 week later by the medial one). Because she tended to keep her left ankle in plantar flexion, electromyography was performed before she was discharged to rule out any concomitant nerve injuries. The electromyogram was consistent with completely normal peroneal and tibial nerves. She was prescribed an ankle-foot orthosis and was discharged to complete a regimen of home exercises.

Compartment syndrome in the lower extremities after prolonged periods of stay in the lithotomy position ensues as a consequence of increased pressure within a limited tissue space that impedes arterial perfusion. It is associated with diverse circumstances and risk factors and may display a surplus of permanent and disabling sequelae. Despite the fact that its exact pathophysiologic mechanisms remain speculative, there are three phases during which the compartment pressure appears to increase: an immediate rise in pressure is seen in the first phase as soon as the legs are placed in the lithotomy position; a second phase of ischemia is due to the disruption of the microarterial circulation of the limb; and eventually, there is a third phase when adequate tissue perfusion is restored. ${ }^{1}$ This self-perpetuating cycle usually ends with decompression by a timely fasciotomy.

A high index of suspicion and prompt diagnosis of compartment syndrome should definitely precede the fasciotomy. Any of the following "six Ps" can alert the physician to its clinical diagnosis: progressive pain out of proportion to the clinical situation, paresthesia, paresis, pain on passive stretch, pink skin, and presence of pulse until compartment pressure exceeds arterial inflow pressures and compartment pressure of greater than $30 \mathrm{mmHg}$. The risk factors (i.e., obesity, peripheral vascular disease, hypotension, hypothermia, hypovolemia, and the type and duration of the lithotomy position) can also be clues for its likely diagnosis.

Unless appropriately handled, untoward neuromuscular sequelae of compartment syndrome may be quite challenging and are generally reported to be in close proportion to the time the patient remains in the lithotomy position (e.g., it is unexpected when the patient is in the position for less than
5 hours $)^{2}$; however, each hour is estimated to increase the risk of motor neuropathy 100 times, and if the patient is in the lithotomy position for more than 6 hours, the scenario may turn out to be irreversible muscle damage. ${ }^{3}$ In our patient, the operation lasted 3.5 hours, and no compressive dressing was applied. Also, the patient had not experienced any hypotension during the operation. Thus, we believe that our incident stemmed from the inappropriate stirrups used during the operation, and fortunately, a possible neurological injury was ruled out by an electromyogram.

Overall, by presenting our patient, we intended to orient clinicians toward being vigilant against such an obtrusive complication as compartment syndrome, especially in patients with the aforementioned risk factors. We also underscore the necessity of its prevention and prompt evaluation of compartment syndrome rather than treating it and hoping a perturbing disability does not ensue.

DOI: 10.1097/01.PRS.0000089274.09090.D5

Levent Özçakar, M.D.
Ibrahim Ötgün, M.D.
Arbay O. Ciftci, M.D.
M. Cemalettin Aksoy, M.D.
Departments of Physical Medicine
$\quad$ Surgery, and Orthopedic Surger
Hacettepe University Medical Scho
Ankara, Turkey
Correspondence to Dr. Özçakar
Yeni Ankara sokak 27/1
Cebeci, Ankara, Turkey
lozcakar@yahoo.com

\section{REFERENCES}

1. Mumtaz, F. H., Chew, H., and Gelister, J. S. Lower limb compartment syndrome associated with the lithotomy position: Concepts and perspectives for the urologist. B.J.U. Int. 90: 792, 2002.

2. Martin, J. T. Compartment syndromes: Concepts and perspectives for the anesthesiologist. Anesth. Analg. 75: $275,1992$.

3. Warner, M. A., Martin, J. T., Schroeder, D. R., Offord, K. P., and Chute, C. G. Lower-extremity motor neuropathy associated with surgery performed on patients in the lithotomy position. Anesthesiology 81: 6, 1994.

\section{FLAP COVERAGE REQUIREMENT FOLLOWING MUSCLE-SLIDING OPERATION FOR MODERATE- TYPE VOLKMANN CONTRACTURE ASSOCIATED WITH POOR SKIN QUALITY ON THE FOREARM}

Sir:

A 14-year-old girl was admitted to our hospital with contracture of her right hand. From her history, it was understood that she had sustained a crush injury to her right forearm 3 months earlier. On the day of the injury, she had been examined in an emergency clinic, and her radiographs had shown no bone fractures. Because the patient's forearm had started to swell, she had been observed for 2 days. Her forearm skin had become necrotic, and following surgical débridement of the necrotic tissues, the area had been covered with a skin graft. By the time she returned for a follow-up visit, contracture had developed on the forearm. The patient 
then consulted us. In her physical examination, scar tissue was visible on the grafted area. There was no sensation deficit. There was a prominent wrist flexion contracture, and the patient was unable to extend her wrist (Fig. 1). A muscle sliding operation was planned to treat Volkmann ischemic contracture. During the operation, under a pneumatic tourniquet, the skin was released to the radial side. The brachioradialis muscle was exposed. The insertion of pronator teres was dissected. The flexor pollicis longus muscle was detached subperiosteally from the radius. Then, the entire flexor muscle mass was shifted distally (Fig. 2). After completion of the muscle-sliding procedure, the pneumatic tourniquet was released and homeostasis was achieved. At that time, it was realized that it would be impossible to cover the muscles with forearm skin that had been grafted earlier without tension. Because the tension might have caused further skin necrosis, a subpectoral flap was elevated and interpolated to the defect (Fig. 3). A dynamic splint was also applied to the hand after the operation, while the patient's forearm was still interpolated with the flap. The base of the flap was cut at the end of week 3. Three months later, the patient had full range of motion (Fig. 4). The only problem the patient reported was the scar tissue on the forearm.

The Kenya-Tsuge classification is a well-known system for classification of Volkmann contracture. It divides the contracture into three types-mild, moderate, and severe-according to the extent of muscle involvement. In the moderate

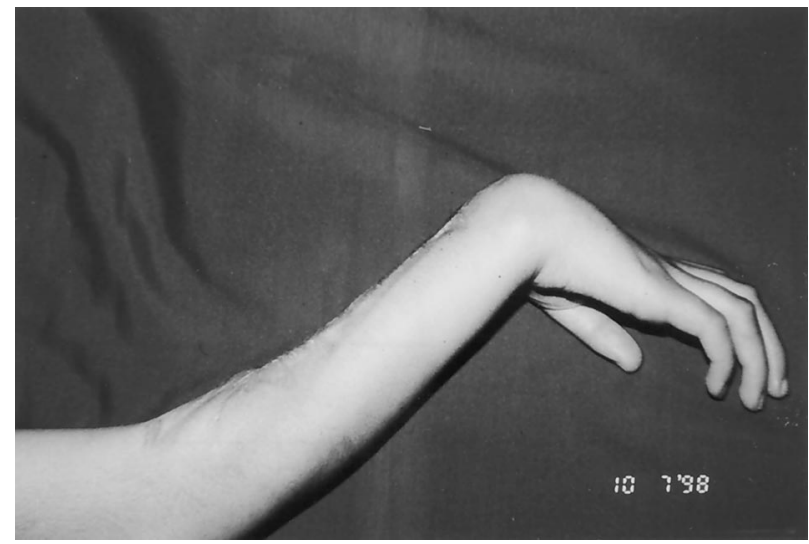

FIG. 1. Preoperative appearance of mild-type Volkmann contracture.

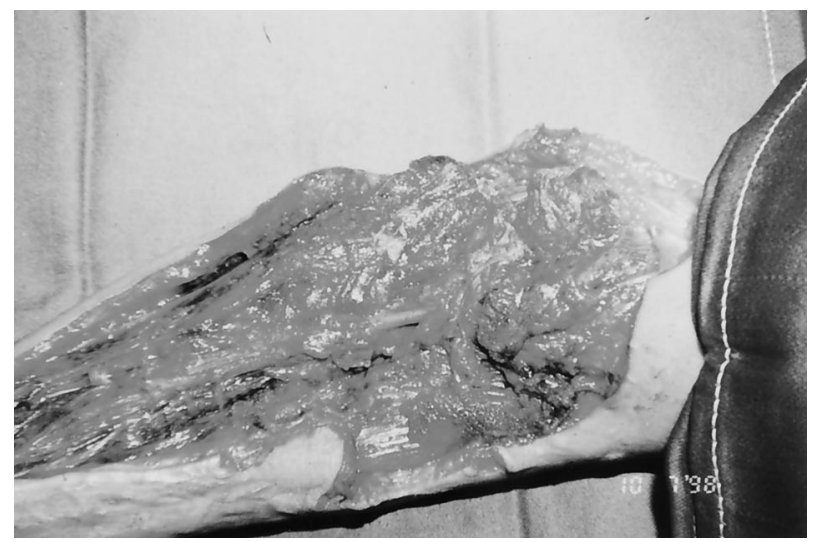

FIG. 2. Intraoperative view of the muscle-sliding operation.

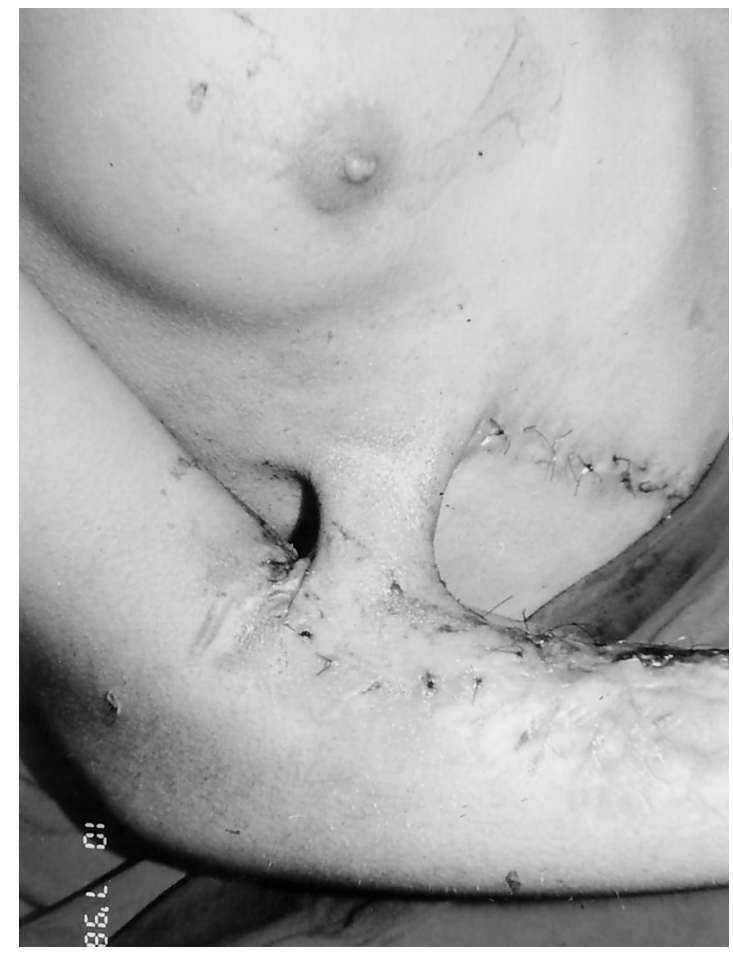

FIG. 3. A subpectoral interpolation flap was selected to cover the defect on the forearm that occurred after the muscle-sliding operation.

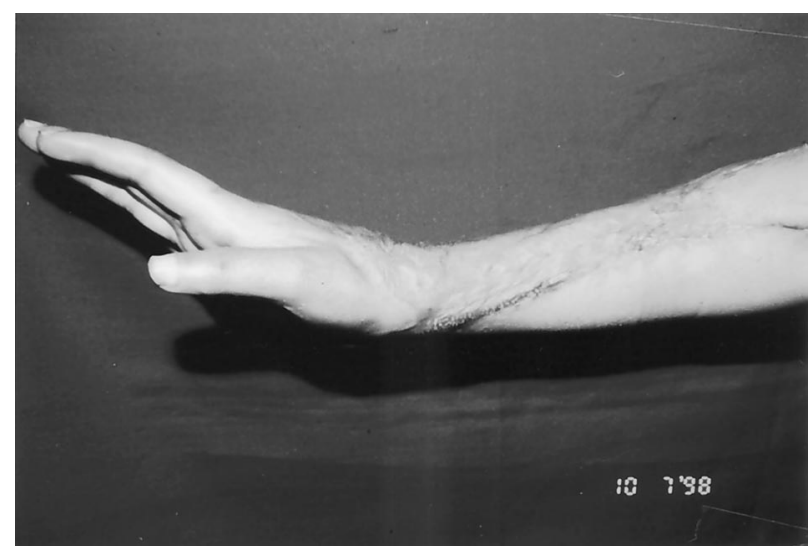

FIG. 4. Late postoperative result is shown.

type, muscular degeneration involves primarily the flexor digitorum profundus and flexor pollicis longus muscles. Flexion contractures of all fingers and the thumb develop. ${ }^{1}$

A muscle-sliding operation is advocated for the treatment of Volkmann contracture. In cases of poor skin quality, including skin-grafted areas, flap coverage may be a necessity, especially following a muscle-sliding operation. ${ }^{2}$ As far as we know, flap coverage as a requirement following a musclesliding operation has not been emphasized. Furthermore, this case reminds us once more that there is only one treatment method for compartment syndrome: immediate decompression of the compartment. When immediate decompression is not performed, later débridement and skin grafting will not prevent Volkmann contracture because the 
skeletal muscles cannot tolerate ischemia after 8 hours. ${ }^{2}$ DOI: $10.1097 / 01 . P R S .0000089275 .72452 . D E$

Mehmet Oğuz Yenidünya, M.D.

Department of Plastic, Reconstructive, and Aesthetic Surgery Fatih University Hospital

Ankara, Turkey

Bülent Adil Tașbaș, M.D.

Department of Orthopedics and Traumatology

Ankara Numune Training and Research Hospital

Ankara, Turkey

Correspondence to Dr. Yenidünya

Fatih University Hospital

Alparslan Turkeş Caddesi, No. 57

Emek, Ankara, Turkey

\section{REFERENCES}

1. Tsuge, K. Management of established Volkmann's contracture. In D. P. Green (Ed.), Operative Hand Surgery, Vol. 1, 2nd Ed. New York: Churchill Livingstone, 1988.

2. Rowland, S. A. Fasciotomy: The treatment of compartment syndrome. In D. P. Green, R. N. Hotchkiss, and W. C. Pederson (Eds.), Green's Operative Hand Surgery, Vol. 1, 4th Ed. New York: Churchill Livingstone, 1999.

\section{AVOIDING INJURY TO THE INFERIOR OBLIQUE MUSCLE DURING LOWER LID BLEPHAROPLASTY}

Sir:

Mowlavi et al. ${ }^{1}$ recently published results of the dissections that they performed with the intent of giving us useful anatomical bony landmarks to avoid injury to the inferior oblique muscle during blepharoplasty surgery.

Although gross anatomical origins and insertions are important, the functional surround is even more important when dealing with a muscle as unusual as the inferior oblique muscle. The inferior oblique muscle is approximately $36 \mathrm{~mm}$ from its origin in an area of the anterior orbital floor that is lateral and inferior to the lacrimal fossa. ${ }^{2}$ From there, it travels laterally and posteriorly in its initial third, penetrates the lower eyelid retractors in its middle third, and then envelops the globe in its final third to insert in a very short (1-mm) tendon on the lateral sclera. This insertion is broad and from about $18 \mathrm{~mm}$ to about $28 \mathrm{~mm}$ posterior to the limbus at the level of the lateral rectus muscle. Transection or injury in this initial first segment frequently does little permanent damage to the function of the inferior oblique muscle. This is because its middle segment, which traverses the capsular palpebral fascial area and the Lockwood ligament, will act as a secondary origin if the first segment has been transected or injured. In the past, when overaction of the inferior oblique muscle was to be surgically eliminated, such transections of the initial first segment were carried out because of their relative ease of performance. ${ }^{3}$ The inferior oblique muscle regained some or all of its functions, and the surgical procedure did not have the desired weakening effect. The second segment, namely the 9 or $10 \mathrm{~mm}$ that underlie the inferior rectus muscle, thus can act as a functional origin. The muscle emerges from underneath the inferior rectus and receives its innervation, a branch of the oculomotor nerve and its blood supply. The most dangerous area in which to transect or injure the infe- rior oblique muscle is in the $2 \mathrm{~mm}$ lateral to the inferior rectus muscle, because injury in this area frequently will injure its nerve supply and blood supply. Other methods of operating on the inferior oblique muscle involve a myomectomy of the muscle itself with or without secondary insertion inferiorly or an inferior oblique recession. Today, of the procedures that are used, only lateral recession or lateral myomectomy is performed to reliably reduce the muscle's function.

With this functional information, the problem of inferior oblique injury after lower lid blepharoplasty can be understood. In the transcutaneous method of lower lid blepharoplasty, the nature of the incision exposes the lateral and central fat areas better than it does the medial fat area. This is because the usual incision is hinged medially and the incision continues outward along the margin of the lower lid and is then redirected downward at the lateral canthus, giving a larger skin flap laterally than medially. The tissue dissection then proceeds from anterior to posterior in the orbit, directly traversing the inferior orbital septum to expose the fat pads. Because of the larger exposure laterally and the fact that the inferior oblique muscle is well above and deep to the septum, fat can be excised with relative impunity laterally. Medially, because of the poorer exposure, fat removal may occur, which risks inferior oblique injury in the first third of the muscle. However, permanent injury here is less common than in the transconjunctival approaches because, as I mentioned above, even transection of the first third of the inferior oblique muscle still allows the middle section of the inferior rectus muscle to act as a secondary origin for the inferior oblique.

However, the transconjunctival approach has a different set of complications. Because of its relatively superior approach from the lower lid conjunctiva and its tunneling beneath the inferior fornix, the conjunctiva is thus separated from the more external capsular palpebral fascia and lid. The surgeon finds himself in no man's land. He is too high to approach the infero-orbital fat directly. $\mathrm{He}$ is behind the inferior orbital septum, and he must tunnel anteriorly to approach the fat. He is already dangerously close to the inferior oblique muscle in both its central third and its lateral third path. Especially at the juncture of the central third underlying the inferior rectus and the Lockwood ligament, there is great danger of transecting the inferior oblique muscle and of injuring the nerve supply as mentioned previously. The best approach to avoid this is to incise the conjunctiva and immediately tunnel anterior and then inferior to the inferior tarsal muscle so that one is below the level of the inferior oblique in a similar position as in the transcutaneous approach. In the medial area, it is possible to injure the inferior oblique muscle through this method, but again, injury in that portion is not as catastrophic as injury in the middle and lateral thirds. I believe that this functional understanding of the anatomy of the inferior oblique muscle rather than a purely anatomic understanding will serve the prospective surgeon well through either the transcutaneous or transconjunctival approach.

The following are a few comments on the diagrams in the article. In Figure 1, there is a diagrammatic representation of the coronal view of the orbit (it is not an anteroposterior view, as labeled) that shows the medial and central fat pads traversed by an inferior oblique muscle and no lateral fat pad. Furthermore, it gives the impression that the anatomic origin of the inferior oblique is a splayed-out group of muscle fibers that bunch together and are only in intimate association with the inferior rectus in the lateral one-quarter of its insertion.

The second diagram, Figure 2, introduces confusion because it refers to some landmark as being in centimeters, 
whereas most of the discussion in the text is given in millimeters. Furthermore, the authors state that, "This incision should be placed $10 \mathrm{~mm}$ inferior to the corneal scleral limbus on the eyelid side." This is extremely confusing because the prospective surgeon is thus urged to measure $10 \mathrm{~mm}$ from the limbus on the globe and then to reflect it onto the lid surface to make the incision. Far better would have been to state that the incision should be made approximately $5 \mathrm{~mm}$ below the inferior border of the tarsal plate, namely that the measurement should be given on the actual structure to be incised. In the last paragraph on page 1321, I believe there is both a misprint and an important conceptual problem. The sentence states, "Specifically, the origin of the inferior oblique muscle is found to be $9.4 \mathrm{~mm}$ lateral to the medial canthus and its insertion $21.7 \mathrm{~mm}$ lateral to the medial canthus." I believe that what the author meant was " $21.7 \mathrm{~mm}$ medial to the lateral canthus." Furthermore, trying to find the insertion of the inferior oblique muscle by using a bony identification point, namely the lateral canthus, is extremely misleading because the insertion of the inferior oblique is a broad tendon, and it is on the globe and is not one point or a small area. DOI: 10.1097/01.PRS.0000089276.49030.F4

\author{
Joshua Frankel, M.D. \\ Eye Care Specialists of Northeastern Pennsylvania \\ 601 Wyoming Avenue \\ Kingston, Pa. 18704
}

\section{REFERENCES}

1. Mowlavi, A., Neumeister, M. W., and Wilhelmi, B. J. Lower blepharoplasty using bony anatomical landmarks to identify and avoid injury to the inferior oblique muscle. Plast. Reconstr. Surg. 110: 1318, 2002.

2. Helveston, E. M. Atlas of Strabismus Surgery. St. Louis: Mosby, 1973. Pp. 16-18.

3. Helveston, E. M., et al. (Eds.). Symposium on Strabismus: Transactions of the New Orleans Academy of Ophthalmology. St. Louis: Mosby, 1978. Pp. 183-184.

\section{REPLY}

Sir:

We thank Dr. Frankel for his interest in our article, "Lower Blepharoplasty Using Bony Anatomical Landmarks to Identify and Avoid Injury to the Inferior Oblique Muscle" (Plast. Reconstr. Surg. 110: 1318, 2002). Dr. Frankel's clinical expertise in oculoplastics is made apparent by his in-depth discussion regarding variable degree of functional muscle deficit depending on the injured segment of the inferior oblique muscle (medial, central, or lateral segment). This clinical insight, as apparent in the initial body of his text, is appreciated.

Unfortunately, Dr. Frankel distracts the reader from this insight when he chooses to barrage the authors with his insignificant and inaccurate criticism. Insignificant comments include fussing over the numerical units used $(10 \mathrm{~mm}$ versus $1 \mathrm{~cm}$ ) or the "view label" of a figure (coronal versus anteroposterior). These criticisms over semantic differences are really unnecessary. Of even more concern are his inaccurate criticisms of the body of the text. He criticizes the authors for presenting anatomic guidelines that have been previously published by other reputed clinicians. If Dr. Frankel feels obliged to comment on previously published material, then he is urged to use the provided references to check his claims. Indeed, Yousif et al. ${ }^{1}$ write, "the origin of the inferior oblique muscle is found $9.4 \mathrm{~mm}$ lateral to the medial canthus and its insertion $21.7 \mathrm{~mm}$ lateral to the medial canthus," as stated in our article and not as incorrectly altered by Dr. Frankel's editorial.

We believe that our published anatomical landmarks utilizing the orbital rim, infraorbital foramen, and supraorbital notch provide dependable landmarks for localization of the inferior oblique muscle course. This knowledge may facilitate orbital fat resection and avoid injury to the inferior oblique muscle during lower lid blepharoplasty.

Arian Mowlavi, M.D.
Bradon J. Wilhelmi, M.D.
The Plastic Surgery Institute
Southern Illinois University School of Medicine
747 N. Rutledge
P.O. Box 19653
Springfield, Ill. 62794-9653
amowlavi@siumed.edu

\section{REFERENCE}

1. Yousif, N. J., Sonderman, P., Dzwierzynski, W. W., and Larson, D. L. Anatomic considerations in transconjunctival blepharoplasty. Plast. Reconstr. Surg. 96: 1271, 1995.

\section{BILATERAL ELASTOFIBROMA AS AN UNUSUAL CAUSE OF SHOULDER PAIN}

Sir:

Elastofibroma is a rare benign entity that was first described by Järvi and Saxen in $1961 .^{1}$ The lesion is eight times more common in women than in men. ${ }^{2}$ It is located at the inferior angle of the scapula. ${ }^{3}$ Bilateral involvement is reported in 10 to 50 percent of cases. ${ }^{4-8}$ Usually it is a slowgrowing tumor, but short mass-doubling times of 4 months have also been described. ${ }^{3}$ The majority of patients with elastofibroma are asymptomatic. Many complain of stiff shoulders or local pain, and some suffer from severe chest pain. ${ }^{7}$ We present a patient with bilateral elastofibroma that had caused persisting shoulder pain for several months after a fall down the stairs.

The patient referred to us was a 46-year-old Italian female pizza baker who had fallen down the stairs months earlier while carrying a sack of flour from the cellar to prepare the pizza dough. She sustained a bilateral contusion of the shoulder girdle. Conventional radiographs ruled out a fracture. Magnetic resonance imaging of the glenohumeral joint showed a superficial rupture of the left supraspinatus tendon and subacromial impingement. At this time, the subscapular region was not examined by magnetic resonance imaging. After several months of conservative treatment without pain relief, an orthopedic surgeon performed arthroscopy-assisted subacromial decompression.

The patient was referred to our department for persistent shoulder pain, especially while kneading pizza dough, and the feeling of repetitive crackling when she elevated her left arm. Physical examination revealed a soft-tissue mass of apple size at the inferior angle of the left scapula that was only perceivable during elevation of the left arm more than 90 degrees. When the left upper extremity was returned to a neutral position, the mass slid back below the inferior margin of the scapula. A computed tomography scan showed a noncapsuled soft-tissue tumor (Fig. 1), and operative revision was 
carried out due to suspicion of an old hematoma. A dense, fibroelastic, noncapsuled mass was found intraoperatively (Fig. 2). The tumor adhered both to the inferior angle of the scapula and to the periosteum of the ribs and was excised in toto. Histologically, the tumor consisted of intermingled eosinophilic collagen fibers and wormlike elastic fibers, fibroblasts, and mature fat cells, thus confirming the diagnosis of elastofibroma (Fig. 3).

The postoperative course was uneventful. The patient was discharged on the twelfth postoperative day. During the rehabilitation period, the patient complained of right-sided shoulder pain with a palpable infrascapular mass (Fig. 4). Total resection again revealed an elastofibroma.

Since Järvi and Saxen ${ }^{1}$ first described elastofibroma in 1961, a few more than 300 cases have been documented in the literature. A Japanese group studied 170 cases. Fifty-five cases occurred in the same family line. Some of the patients had multiple elastofibroma, and one patient had seven masses simultaneously. Of the patients, 158 patients were female and only 12 were male. The average age was 70 years (range, 35 to 94 years). ${ }^{7}$ The youngest patient ever reported was a 6 -year-old girl. ${ }^{8}$ One patient was observed over a period of 67 years before the bilateral tumors were removed surgically due to increasing pain. ${ }^{7}$

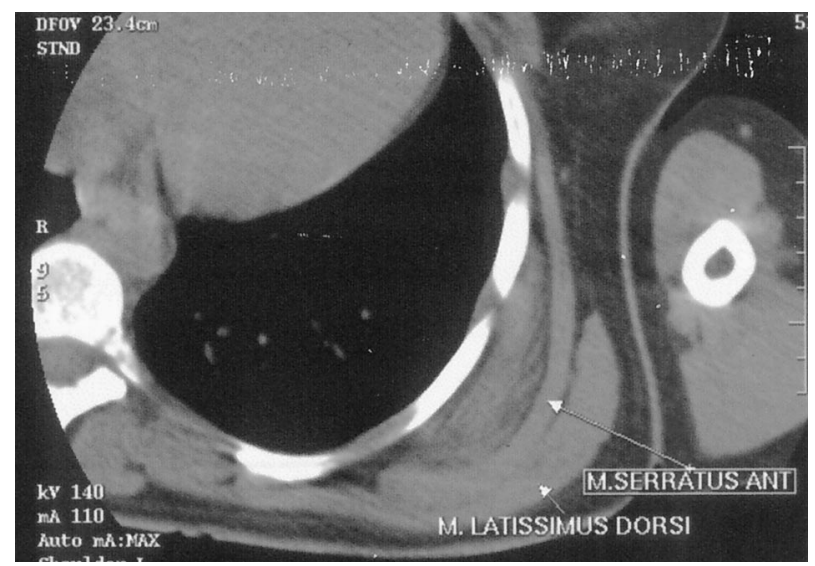

FIG. 1. The computed tomography scan of the left scapular region shows a tumorous mass deep to the serratus anterior muscle. The tissue predominantly has muscle attenuation interspersed with strands of fat.

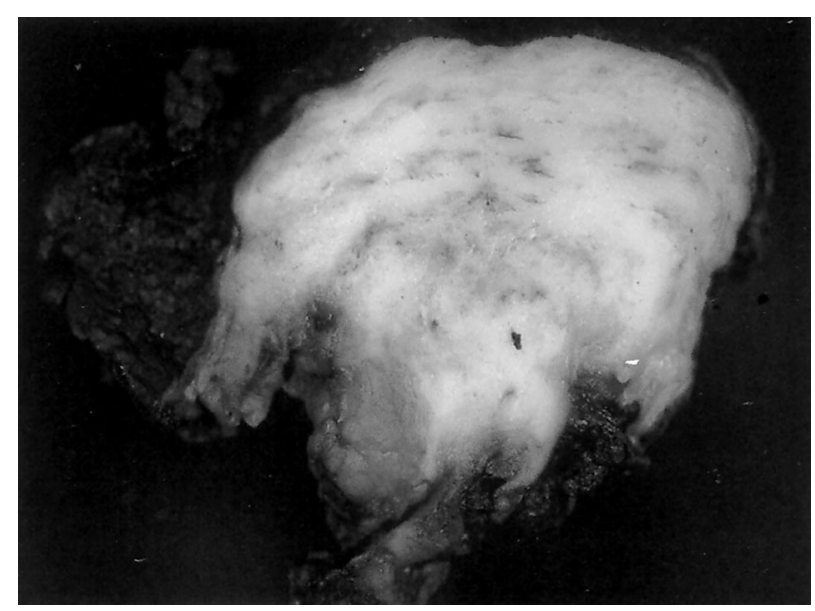

FIG. 2. The gross appearance of the bisected tumor.

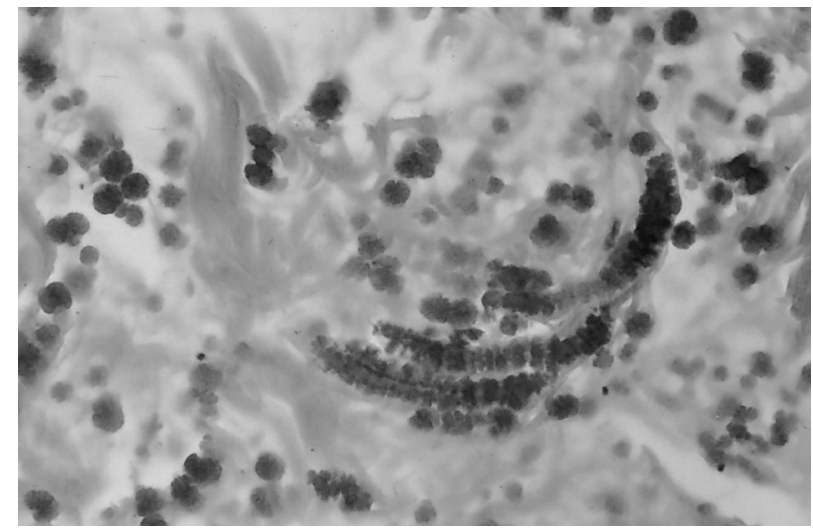

FIG. 3. Elastic staining of the tumor demonstrates numerous globular, wormlike elastic materials. Central cores are visible within beadlike elastic fibers (elastin stain, $\times 400$ ).

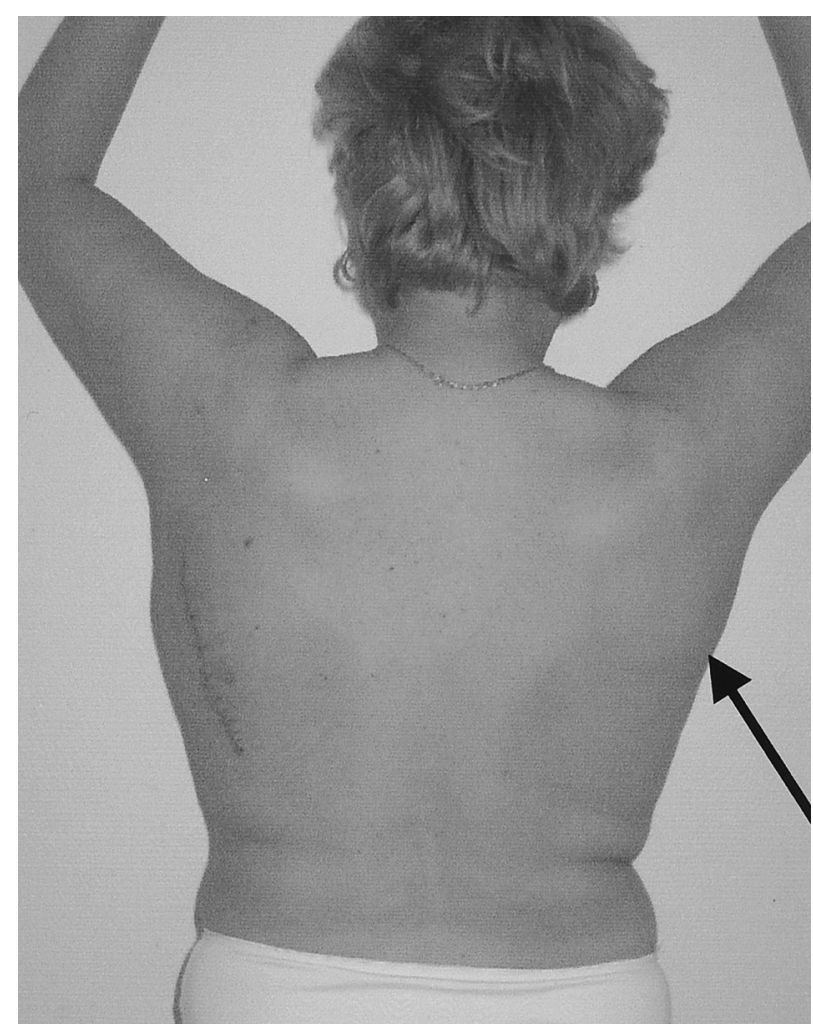

FIG. 4. Clinical photograph of the dorsal aspect of the patient 10 days after operation of the left-sided lesion. The tumor protrudes from beneath the scapula during elevation of the right arm. The right side was operated on 10 days later.

Elastofibroma is characterized histologically by the presence of abnormal elastic fibers within a stroma of fibroadipose tissue. ${ }^{9}$ Uncommon locations have been reported, including the deltoid muscle, olecranon, thoracic wall, vertebral canal, ischial tuberosity, greater trochanter, foot, inguinal areas, orbita, stomach, greater omentum, ${ }^{2}$ and even the tricuspid valve. ${ }^{2,10}$ When the patients hold their arms slightly elevated forward and adducted, the scapula is displaced laterally and the lesion protrudes underneath the scapula. 
Whether elastofibroma is a true neoplasm or a reactive fibrous lesion that produces not only collagen but also abnormal elastic fibers is controversial and remains undetermined ${ }^{8}$ The lesions have a characteristic location and a specific magnetic resonance imaging appearance, which allows accurate prospective diagnosis. The magnetic resonance features are different from those of most other soft-tissue tumors, reflecting entrapped fat within a predominantly dense fibrous mass. On T1- and T2-weighted images, it appears as a soft-tissue mass with signal intensity of skeletal muscle interlaced with streaks with the signal intensity of fat. On computed tomography scans, it is a poorly defined, inhomogeneous mass with attenuation of skeletal muscle, again containing linear streaks of fat. ${ }^{11,12}$

The importance of recognizing the benign nature of this lesion to avoid an unnecessary operation is apparent. DOI: 10.1097/01.PRS.0000089278.52641.6A

Steffen Heck, M.D.

Gausepohl Thomas, M.D.

Konrad Mader, M.D.

Andreas P. Wulke, M.D.

Dietmar Pennig, M.D.

Department of Trauma Surgery and Hand and Reconstructive Surgery

St. Vinzenz Hospital

Cologne, Germany

Walter Mellin, M.D.

Institute for Pathology, Cytology, and Cytogenetics

Cologne, Germany

Correspondence to Dr. Heck

Department of Trauma Surgery and Hand and Reconstructive Surgery

St. Vinzenz Hospital

Merheimer St. 221-223

D-50733 Cologne, Germany

thehecks@t-online.de

\section{REFERENCES}

1. Järvi, O., and Saxen, E. Elastofibroma dorsi. Acta Pathol. Microbiol. Scand. Suppl. 144: 83, 1961.

2. Bennett, K. G., Organ, C. H., Cook, S., and Pitha, J. Bilateral elastofibroma dorsi: A case report. Surgery 103: 605, 1988.

3. Turna, A., Yilmaz, M. A., Ürer, N., Bedirhan, M. A., and Gürses, A. Bilateral elastofibroma dorsi. Ann. Thorac. Surg. 73: 630, 2002.

4. Buchholz, A., and Wellner, K. Das Elastofibrom dorsi. Zentralbl. Chir. 115: 1327, 1990.

5. Enzinger, F. M., and Weiss, S. W. Soft Tissue Tumors. St. Louis: Mosby, 1983. P. 33.

6. Hoffman, J. J., Klein, M. H., and McLenerney, V. K. Bilateral elastofibroma: A case report and review of the literature. Clin. Orthop. 325: 245, 1996.

7. Nagamine, N., Nohara, Y., and Ito, E. Elastofibroma in Okinawa: A clinopathologic study of 170 cases. Cancer 50: 1794, 1982.

8. Marin, M. L., Perzin, K. H., and Markowitz, A. M. Elastofibroma dorsi: Benign chest wall tumor. J. Thorac. Cardiovasc. Surg. 98: 234, 1989.

9. Kobayashi, H., Hirokawa, M., Shimizu, M., et al. Scrape cytology of elastofibroma: Report of a case with diagnostic cytologic features. Acta Cytol. 43: 485, 1999.

10. Mohan, J. C., Goel, P. K., Gambhir, D. S., Khanna, S. K., and Arora, R. Calcified mobile papillary fibroelastoma of the tricuspid valve: A case report. Indian Heart J. 39: 237, 1987.

11. Kransdorf, M. J., Meis, J. M., and Montgomery, E. Elastofibroma: MR and CT appearance with radiologic-pathologic correlation. A.J.R. Am. J. Roentgenol. 159: $575,1992$.

12. Nakano, T., Tsutsumi, Z., Hada, T., and Higashino, K. Radiological manifestation of elastofibroma: A case report and review of the literature. Br. J. Radiol. 64: 1069, 1990.

\section{TREATMENT OF MANDIBLE FRACTURES USING BIOABSORBABLE PLATES}

Sir:

As surgeons at an experienced clinic in which approximately 200 patients per year are operated on, we wish to commend and criticize Drs. Kim and Kim's article entitled "Treatment of Mandibular Fractures Using Bioabsorbable Plates" (Plast. Reconstr. Surg. 110: 25, 2002).

The classic tenet for closed reduction and intermaxillary fixation is to maintain the fixation 3 to 4 weeks for the subcondylar and 4 to 6 weeks for the other areas of the mandible. We have shortened the fixation period up to 3 to 4 weeks for all areas of the mandible since $1987 .{ }^{1}$ During the rigid fixation procedures, intermaxillary fixation is used in restoring and securing normal occlusion and can be removed by the end of the operation or within the first postoperative week. In this regard, it seems unlikely to use both bioabsorbable plates and intermaxillary fixation for 2 to 3 weeks in eight cases, as reported in the study. Keeping the intermaxillary fixation for an additional 1 or 2 weeks would have sufficed for the bone healing without the extra disadvantages of the bioabsorbable screws and plates. ${ }^{2,3}$ The authors also reported that all the patients operated on were given a liquid or soft diet for 1 month after the operation, regardless of the intermaxillary fixation period or osteosynthesis material. This is another contradictory statement on behalf of the advantage of rigid fixation, which leads to early jaw movements and a normal diet. $^{4}$

There is a statement that rigid metallic fixation deprives bone of normal stress and prevents the rapid formation of primary callus. Is this an acceptable view per the literature on facial bone healing, which has an intramembranous developmental origin, and on any rigid fixation modality, as in the study $?^{5-7}$ Application of bioabsorbable materials on human beings could make the study more valuable after basic science studies, including stress testing, were performed, especially on the corpus and angulus regions. With respect to obtaining satisfactory results, indications should be clarified according to mandibular regions.

Complications such as infection are often associated with the method of treatment. The rate of complications would be lowered to 3 percent after experience was gained with the plating system. ${ }^{8-10}$ With an 8.1 percent infection rate, bioabsorbable plates seem to cause a higher complication rate. The subcondylar area, angle, and cuspid region and the mental foramen are the naturally weak areas of the mandible. The 
holes drilled for the screws also involve the risk of refracture, which is why heat necrosis of bone should be avoided at all times. From this point of view, the osteolytic changes seen around the self-reinforced absorbable polylactide screws in 27 percent of cases may cause a high rate of additional weak areas in the mandible.

In conclusion, because of the above-mentioned reasons, we do not have confidence in the ability to anatomically reduce and stabilize the fractured fragments with the selfreinforced poly-L-lactide multilayer plates.

DOI: $10.1097 / 01 . P R S .0000089332 .70602 .13$

Turgut Ortak, M.D.

R. Erkin Ünlü, M.D.

Asu Deniz Yılmaz, M.D.

Ömer Sensöz, M.D.

Department of Plastic and Reconstructive Surgery

Ankara Numune Training and Research Hospital Ankara, Turkey

Correspondence to Dr. Ortak

Resat Nuri Sok.

82/12 Doruk Apt., Y. Ayrancı

Ankara, Turke)

drtortak@yahoo.com

\section{REFERENCES}

1. Şensöz, Ö., Erdoğan, B., Kanmaz, B., and Koçer, U. Analysis of the mandibular fractures and shortening the fixation period in treatment. Turk. J. Res. Med. Sci. 5: 83, 1987.

2. Schmidt, B. L., Kearns, G., Gordon, N., and Kaban, L. B. A. Financial analysis of maxillomandibular fixation versus rigid internal fixation for treatment of mandibular fractures. J. Oral Maxillofac. Surg. 58: 1206, discussion 1210, 2000.

3. Haers, P. E., and Sailer, H. F. Biodegradable self-reinforced poly-L/DL-lactide plates and screws in bimaxillary orthognathic surgery: Short term skeletal stability and material related failures. J. Craniomaxillofac. Surg. 26: 363, 1998.

4. Jaques, B., Richter, M., and Arza, A. Treatment of mandibular fractures with rigid osteosynthesis: Using the AO system. J. Oral Maxillofac. Surg. 55: 1402, discussion $1406,1997$.

5. Haug, R. H., and Schwimmer, A. Fibrous union of the mandible: A review of 27 patients. J. Oral Maxillofac. Surg. 52: 832, 1994.

6. Hoffman, W. Y., Barton, R. M., Price, M., and Mathes, S.J. Rigid internal fixation vs. traditional techniques for the treatment of mandible fractures. J. Trauma 30: 1032, 1990.

7. Bagby, G. W., and Janes, J. M. The effect of compression on the rate of fracture healing using a special plate. Am. J. Surg. 95: 761, 1958.

8. Iızuka, T., Lindqvist, C., Hallikainen, D., and Paukku, P. Infection after rigid internal fixation of mandibular fractures: A clinical and radiologic study. J. Oral Maxillofac. Surg. 49: 585, 1991.

9. Aksoy, E., Ünlü, R. E., and Şensöz, Ö. A retrospective study on epidemiology and treatment of maxillofacial fractures. J. Craniofac. Surg. 13: 772, 2002.
10. Ezsias, A., and Sugar, A. W. Pathological fractures of the mandible: A diagnostic and treatment dilemma. $\mathrm{Br}$. J. Oral Maxillofac. Surg. 32: 303, 1994.

\section{REANIMATION OPTIONS IN PATIENTS WITH HEMIFACIAL MICROSOMIA AND MARGINAL MANDIBULAR NERVE PALSY}

Sir:

Hemifacial microsomia is one of the most commonly presenting craniofacial anomalies, with an incidence of approximately one in 5000 live births. ${ }^{1,2}$ Although in 10 to 30 percent of cases it manifests bilaterally, when almost universally asymmetric, more commonly it affects the right side of the face in boys. ${ }^{3,4}$ The principal defects seen, as classically described by Gorlin et al., ${ }^{5}$ are hypoplasia of the mandible, macrostomia, and microtia. The condition has a varied phenotype and can be associated with a variety of other congenital anomalies; some advocate solitary microtia as the simplest manifestation of the condition. ${ }^{6}$ Soft-tissue deficiency and hypoplasia of the muscles of mastication are intimately associated with the degree of mandibular deformity, ${ }^{7}$ and cranial nerve involvement is seen in approximately 20 to 45 percent of cases. ${ }^{8,9}$ The degree of external ear deformity, rather than other bony or soft-tissue defects, is a predictor of seventh nerve involvement. ${ }^{8,10}$ Etiology of the condition remains unclear,, $211-14$ but facial palsy associated with hemifacial microsomia is thought to be secondary to abnormal middle ear seventh nerve pathways and fallopian canal atresia. ${ }^{8,15}$ Most often, marginal mandibular paralysis is seen, although paralysis of the complete facial musculature may be present. ${ }^{10,16}$

Surgical options for the paralyzed marginal mandibular branch in the normal face have been reported using a variety of muscle transpositions to the lower lip, including the orbicularis oris, platysma, and anterior belly of digastric muscles, all with pleasing results. ${ }^{17-19}$ Free-muscle transfer has been used to recreate the lower lip depressor function in isolated deficits and as a double muscle transfer in cases of complete unilateral palsy. ${ }^{19,20}$ Reinnervation using hypoglossal nerve transfer to the lower lip musculature has had less satisfactory results. ${ }^{18}$ Previous studies on marginal mandibular branch reanimation, assessing all the above techniques, have concluded that local muscle transfers offer the best results in the otherwise normal face..$^{18,19}$

In our unit, we have encountered three patients with hemifacial microsomia and an isolated paralysis of the marginal mandibular branch of the facial nerve. As stated above, it is, under normal circumstances, preferable to use a local muscle transposition flap for reanimation; our flap of choice is the anterior belly of digastric muscle. In each of these patients, there was no platysma muscle or anterior belly of digastric muscle; the procedure was therefore abandoned in two of these patients. In the third case, a mylohyoid flap, previously described following cadaveric anatomical dissection, ${ }^{21}$ was used for reanimation. These cases illustrate the difficulties faced when attempting to restore lower lip function in those with hemifacial microsomia. Direct neurotization using crossfacial nerve grafts ${ }^{22,23}$ is generally inappropriate due to the late presentation of these cases. Beyond 1 year, the success achieved using this technique or reinnervation with the hypoglossal nerve is less than optimal ${ }^{23}$ because of atrophy of the musculature. ${ }^{24}$ Alongside the hypoplastic masticatory muscles, it would appear that other muscles can also be hypoplastic or absent, perhaps by virtue of shared innervation with the masticatory muscles (in the case of the anterior belly of 
digastric muscle) or as a result of involvement of the cervical branch of the facial nerve (with platysma), thus ruling out these common muscle transfers. Previous authors have commented on the value of microneurovascular muscle transfer in cases of complex facial hypoplastic syndromes, and a recent series reported good results using this technique applied to marginal mandibular branch paralysis in hemifacial microsomia. ${ }^{19,25}$ Despite concerns about potentially hypoplastic vessels, the senior author has found, as others have also report$\mathrm{ed},{ }^{25}$ that the vessels are of adequate caliber but located aberrantly.

We would like to draw readers' attention to this clinical problem and advocate caution when planning reanimation procedures in patients with hemifacial microsomia. In such cases, it is our view that free-tissue transfer is the procedure of choice because the anterior belly of digastric muscle cannot be relied upon.

DOI: 10.1097/01.PRS.0000089280.57545.96

Anthony MacQuillan, M.R.C.S.

Martin Vesely, F.R.C.S.

Douglas Harrison, F.R.C.S.

Adriaan Grobbelaar, M.Med.(Plast.), F.C.S.(S.A.), F.R.C.S.(Plast.)

The RAFT Institute of Plastic Surgery

Mount Vernon Hospital

Northwood, Middlesex, United Kingdom

Correspondence to Dr. MacQuillan

The RAFT Institute of Plastic Surgery

Mount Vernon Hospital

Rickmansworth Road

Northwood, Middlesex HA6 2RN

United Kingdom

antmacquillan@hotmail.com

\section{REFERENCES}

1. Grabb, W. C. The first and second branchial arch syndrome. Plast. Reconstr. Surg. 36: 485, 1965.

2. Poswillow, D. The pathogenesis of first and second branchial arch syndrome. Plast. Reconstr. Surg. 35: 302, 1973.

3. Ross, R. B. Lateral facial dysplasia (first and second branchial arch syndrome, hemifacial microsomia). Birth Defects Orig. Artic. Ser. 11: 51, 1975.

4. Cousley, R., and Calvert, M. Current concepts in the understanding and management of hemifacial microsomia. Br. J. Plast. Surg. 50: 536, 1997.

5. Gorlin, R. J., Jue, K. L., Jacobsen, V., and Goldschmidt, E. Oculoauriculovertebral dysplasia. J. Pediatr. 63: 991, 1963.

6. Bennun, R. D., Mulliken, J. B., Kaban, L. B., and Murray, J. E. Microtia: A microform of hemifacial microsomia. Plast. Reconstr. Surg. 76: 859, 1985.

7. Kane, A. A., Lo, L. J., Christensen, G. E., Vannier, M. W., and Marsh, J. L. Relationship between bone and muscles of mastication in hemifacial microsomia. Plast. Reconstr. Surg. 99: 990, 1997.

8. Bassila, M. K., and Goldberg, R. The association of facial palsy and/or sensorineural hearing loss in patients with hemifacial microsomia. Cleft Palate J. 26: 287, 1989.

9. Vento, A., LaBrie, R., and Mulliken, J. The OMENS classification of hemifacial microsomia. Cleft Palate Craniofac. J. 28: 68, 1991.
10. Murray, J. E., Kaban, L. B., and Mulliken, J. B. Analysis and treatment of hemifacial microsomia. Plast. Reconstr. Surg. 74: 186, 1984.

11. Cousley, R. R. J., and Wilson, D. J. Hemifacial microsomia: Developmental consequence of perturbation of the auriculofacial cartilage model. Am.J. Med. Genet. 42: 461, 1992.

12. Akyuz, S., Mumcu, G., Atasu, M., et al. Hemifacial microsomia: Oral, clinical, genetic and dermatoglyphic findings. J. Clin. Pediatr. Dent. 23: 63, 1998.

13. de Ravel, T. J., Legius, E., Brems, H., Van Hoestenberghe, R., Gillis, P. H., and Fryns, J. P. Hemifacial microsomia in two patients further supporting chromosomal mosaicism as a causative factor. Clin. Dysmorphol. 10: 263, 2001.

14. Jacobsson, C., and Granstrom, G. Clinical appearance of spontaneous and induced first and second branchial arch syndromes. Scand. J. Plast. Reconstr. Surg. Hand Surg. 31: 125, 1997.

15. Converse, J. M., Coccaro, P. J., Becker, M., and WoodSmith, D. On hemifacial microsomia: The first and second branchial arch syndrome. Plast. Reconstr. Surg. 51: 268, 1973

16. Mulliken, J. B., and Kaban, J. B. Analysis and treatment of hemifacial microsomia in childhood. Clin. Plast. Surg. 14: 91, 1987.

17. Pluckett, C. L., Neale, H. W., and Pickrell, K. L. Dynamic correction of unilateral paralysis of the lower lip. Plast. Reconstr. Surg. 55: 397, 1975.

18. Terzis, J. K., and Kalantarian, B. Microsurgical strategies in 74 patients for restoration of dynamic depressor muscle mechanism: A neglected target in facial reanimation. Plast. Reconstr. Surg. 105: 1917, discussion 1932, 2000.

19. Tulley, P., Webb, A., Chana, J. S., et al. Paralysis of the marginal mandibular branch of the facial nerve: Treatment options. Br. J. Plast. Surg. 53: 378, 2000.

20. Ueda, K., Harii, K., and Yamada, A. Free vascularized double muscle transplantation for the treatment of facial paralysis. Plast. Reconstr. Surg. 95: 1288, 1995.

21. Aszmann, O., Ebmer, J., and Dellon, A. The anatomic basis for the innervated mylohyoid/digastric flap in facial reanimation. Plast. Reconstr. Surg. 102: 369, 1998.

22. Inigo, F., Ysunza, A., Ortiz-Monasterio, F., and DruckerColin, R. Early postnatal treatment of congenital facial palsy in patients with hemifacial microsomia. Int. J. Pediatr. Otorhinolaryngol. 23: 57, 1993.

23. Ysunza, A., Inigo, F., Rojo, P., Drucker-Colin, R., and Ortiz-Monasterio, F. O. Congenital facial palsy and crossed facial nerve grafts: Age and outcome. Int. J. Pediatr. Otorhinolaryngol. 36: 125, 1996.

24. Ferreira, M. C. Cross facial nerve grafting. Clin. Plast. Surg. 11: 211, 1984.

25. Takushima, A., Harii, K., Asato, H., and Yamada, A. Neurovascular free-muscle transfer to treat facial paralysis associated with hemifacial microsomia. Plast. Reconstr. Surg. 109: 1219, 2002.

\section{AUTOSTATIC SYNDROME IN ASSOCIATION WITH FACIAL NERVE TRANSPLANTATION}

Sir:

Figure 15 in Dr. Wei Wang et al.'s article on facial reanimation (Neurovascular Musculus Obliquus Internus Abdominis Flap Free Transfer for Facial Reanimation in a Single 
Stage. Plast. Reconstr. Surg. 110: 1430, 2002) confirms the occurrence of autostatic syndrome. ${ }^{1}$

The syndrome almost invariably occurs after cross-facial nerve grafting, because axons destined for the orbicularis oris also innervate the muscle flap. This makes the angle of the mouth move outward when the lips are pursed, instead of medially.

However original, Dr. Wang's technique cannot prevent this. We must continue seeking other solutions in the reanimation of facial paralysis.

DOI: 10.1097/01.PRS.0000089333.22025.DC

\author{
J.-P. A. Nicolai, M.D. \\ Department of Surgery \\ Groningen University Hospital \\ P.O. Box 30001 \\ 9700 RB Groningen, The Netherlands
}

\section{REFERENCE}

1. Nicolai, J.-P. A., and Robinson, P.H. Autostatic syndrome after cross-facial nerve transplantation. Ann. Plast. Surg. 19: 337, 1987.

\section{MEDIAL PEDICLED ORBICULARIS OCULI FLAP}

Sir:

We read with great interest the article by Jelks et al., entitled "Medial Canthal Reconstruction Using a Medially Based Upper Eyelid Myocutaneous Flap" (Plast. Reconstr. Surg. 110: 1636, 2002). Indeed, reconstruction of the media canthal area is a frequently encountered problem after tumor ablations, and we have been using a flap from the upper eyelid for this purpose. Our technique was published in 2001 with the title "Medial Pedicled Orbicularis Oculi Flap for Medial Canthal Resurfacing." ${ }^{1}$ Furthermore, we have transferred this flap not only to the medial canthal region but also to the nearby defects. These extended applications of the flap were published in December of 2002, ${ }^{2}$ coinciding with the abovementioned article by Jelks et al. We would like to comment on some points since we have used the same flap for several years.

1. We agree with the authors that the eyelid skin is a better alternative in the reconstruction of the medial canthal area, the lateral nasal area, and the bony nasal dorsum than the classic methods, such as the frontal or the glabellar flaps, which are thicker.

2. For the defects confined to the median canthal region, we prefer to transfer the flap from the contralateral eyelid. ${ }^{1}$ This has two advantages. First, as the flap extends to the opposite site, the deformity caused by the pedicle at the pivot point is less pronounced. Second, we are skeptical about the ipsilateral flap vascularity, which can be harmed at the medial canthal level. Although the flap has a rich blood supply, as described by the authors, we still think that the untouched contralateral site is a better option as the donor site.

3. The medial canthal region is rich in vascular arcades. This area receives its blood supply from both the external carotid system (i.e., the infratrochlear and angular arteries) and the internal carotid system (i.e., the supraorbital, supratrochlear, dorsal nasal, and medial palpebral arteries). ${ }^{3}$ The medial palpebral artery is the major contributor to the medial pedicled orbicularis oculi flap. However, due to the rich vascular connections, the flap can be
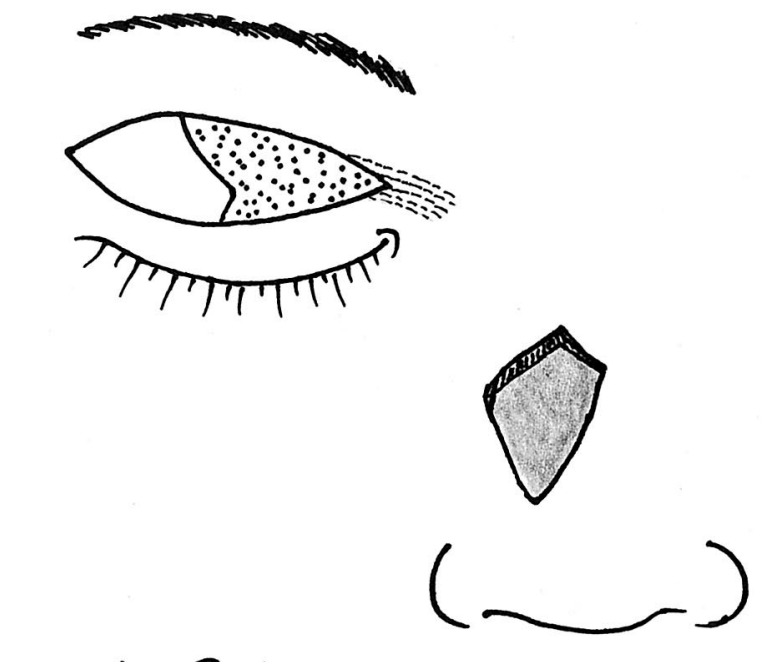

Erdenterel
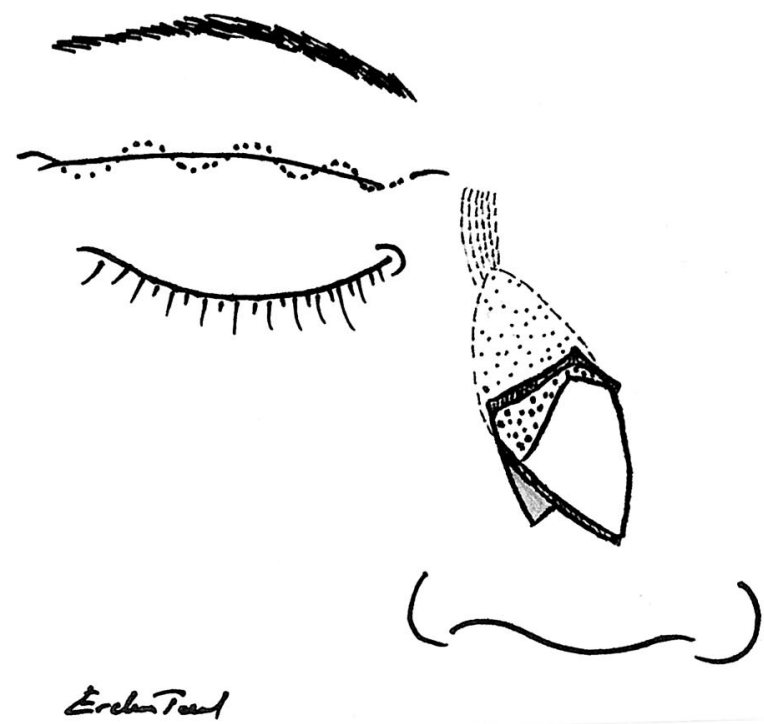

FIG. 1. The skin island is marked according to the defect area. (Above) The dotted area is deepithelialized. (Below) The flap is transferred through the subcutaneous tunnel.

nourished from the external carotid system (angular artery) as well. Therefore, there is no need to pay any attention to the isolation of the medial palpebral perforators while dissecting the flap, contrary to what the authors suggest. The dissection of the flap ends at the medial canthal region, ensuring the preservation of the angular system, which is located medial to the medial canthus.

4. In our article, we have described the creation of a subcutaneous tunnel that allows us to transfer this flap as an interpolation flap. Thus, the skin between the flap and the defect is untouched, extra scar is avoided, and better aesthetic results are achieved (Fig. 1).

5. The flap size is directly proportionate to the skin excess of the upper lid. Therefore, careful patient selection is important. Even the smaller defects may be difficult to cover in a patient with minimum skin excess of the upper lid. 
We believe this flap will be used frequently in the future.

DOI: 10.1097/01.PRS.0000089282.29835.4C

Erdem Tezel, M.D.

Ahmet Sönmez, M.D.

Ayhan Numanoğlu, M.D.

Department of Plastic and Reconstructive Surgery

Marmara University School of Medicine

Istanbul, Turkey

Correspondence to Dr. Tezel

Marmara Üniversitesi Hastanesi

Plastik ve Reconstrüktif Cerrahi A.D.

Tophaneliolu Cad. No. 13/15

81190 Altunizade, Istanbul, Turkey

erdemtezel@hotmail.com

\section{REFERENCES}

1. Tezel, E., Sönmez, A., and Numanoğlu, A. Medial pedicled orbicularis oculi flap for medial canthal resurfacing. Ann. Plast. Surg. 47: 213, 2001.

2. Tezel, E., Sönmez, A., and Numanoğlu, A. Medial pedicled orbicularis oculi flap. Ann. Plast. Surg. 49: 599, 2002.

3. Clemente, C. D. (Ed.). Gray's Anatomy of the Human Body, 30th Ed. Philadelphia: Lea \& Febiger, 1985. Pp. 685688.

\section{EFFECT OF ULTRASOUND-ASSISTED LIPOSUCTION ON SKIN PERFUSION}

Sir:

We read with great interest the article by Gupta et al., entitled "Effect of Liposuction on Skin Perfusion" (Plast. Reconstr. Surg. 110: 1748, 2002). We congratulate the authors on their well-delineated study and for their efforts to elucidate the effects of ultrasound-assisted liposuction on tissues, comparing it to conventional wet liposuction. The authors used the laser Doppler flowmeter to measure skin perfusion, and the results showed a decrease in skin perfusion in the conventional wet liposuction group soon after infiltration with a wetting solution (containing vasoconstrictor), which persisted during the first week of follow-up. In the ultrasoundassisted group, after the same decrease related to the wetting solution, the skin perfusion increased (above the preoperative level) from the first hour until the first week postoperatively. Such results are undoubtedly interesting.

However, we cannot agree with some inferences that the authors elaborate on in the Discussion. They argue that the mechanism of action of ultrasound-assisted liposuction is more selective to adipocytes and infer that this represents less damage to adjacent tissues, which would explain the enhanced skin perfusion in this group. Having such reasoning as a basis, one could consider this study as clinical evidence of the selectivity of ultrasound-assisted technique in vivo. It sounds logical, and the authors' Discussion indeed drives us to such a conclusion.

Yet when we analyze this logical sequence, there are points on which we do not agree. First, most of the evidence of the so-called selectivity to adipocytes in ultrasound-assisted liposuction is found in in vitro studies. Second, less damage to adjacent tissues has not been demonstrated in vivo, and clinical evidence (such as the reports of surgical complications, namely skin necrosis on areas subjected to ultrasound-assisted liposuction) does not favor such a hypothesis. Third, enhanced skin perfusion can be secondary to an inflammatory response. Local vasodilation and increased blood flow are present in the early phases of inflammation. ${ }^{1}$ Thus, the enhanced skin perfusion could indicate tissue damage, not the opposite.

To clarify the subject, further studies would be necessary, for example, with histopathologic or biochemical analysis of tissues subjected in vivo to different techniques of liposuction. One such study was concluded by Cárdenas-Camarena et al. and entitled "Laboratory and Histopathologic Comparative Study of Internal Ultrasound-Assisted Lipoplasty and Tumescent Lipoplasty," published in this Journal in September of 2002 (Plast. Reconstr. Surg. 110: 1158, 2002). Their conclusions are indeed somewhat different from those of Gupta et al. In this study, the indicators of tissue damage showed statistically significant higher levels in the group submitted to ultrasound-assisted liposuction.

There is certainly much more to be elucidated on this subject. Even though we do not agree with the authors' inferences, they must be congratulated on a well-conducted study, which certainly adds information to the theme and incites further discussion.

DOI: 10.1097/01.PRS.0000089283.41138.3F

\author{
Victor Vieira Orsi, M.D. \\ Antônio Carlos Pinto Oliveira, M.D. \\ Porto Alegre, Brazil \\ Correspondence to Dr. Orsi \\ Rua Vieira de Castro 275/401 \\ CEP 90.040-320 \\ Porto Alegre, Brazil \\ victorvorsi@uol.com.br
}

\section{REFERENCE}

1. Cotran, R. S., Kumar, V., and Robbins, S. L. (Eds.). Inflammation and repair. In Robbins Pathologic Basis of Disease, 4th Ed. Philadelphia: Saunders, 1989. Pp. 3986.

\section{SAFER LIPOSUCTION FOR HOSPITAL STAFF}

Sir:

We report a simple and cost-effective technique designed to reduce the risk to the operating surgeon and operating room staff during liposuction procedures.

Since Teimourian and Fisher ${ }^{1}$ first described liposuction in 1981, a considerable volume of research has been published on the risks to the patient and potential complications. ${ }^{2,3}$ Relatively few authors have addressed the potential risks to the surgeon and associated operating room staff. The advent of wet, superwet, and tumescent techniques has led to the infusion of increasing amounts of fluid before suction lipectomy. ${ }^{4,5}$ Ultrasound is often used to facilitate tissue removal. Many surgeons now prefer the use of syringe-generated suction to machine-driven systems. This generates large volumes of fluid-fat mix that must be transferred from syringes to a suitable container and subsequently disposed of.

The surgical field contains potentially infectious organisms that may be released into the operating room environ- 
ment as a liposanguinous aerosol. Although no cases of clinical infection have been reported in the literature, Higashi et al. ${ }^{6}$ have demonstrated that hepatitis $\mathrm{C}$ virus is found in tissue fluid produced by ultrasonic dissection. Cukier et al. ${ }^{7}$ have demonstrated that viable Pseudomonas aeruginosa can be aerosolized by suction lipoplasty and remains present in the environment for a number of hours. This represents a significant risk to operating room personnel. Almost any pathogen is capable of breaching host defenses when aerosolized and inhaled deep into lung parenchyma. Case reports in the literature document aerosol-based infection with many organisms, including Influenza virus, Lassa virus, Gram-negative bacilli, Mycobacterium intracellulare, Mycobacterium scrofula-

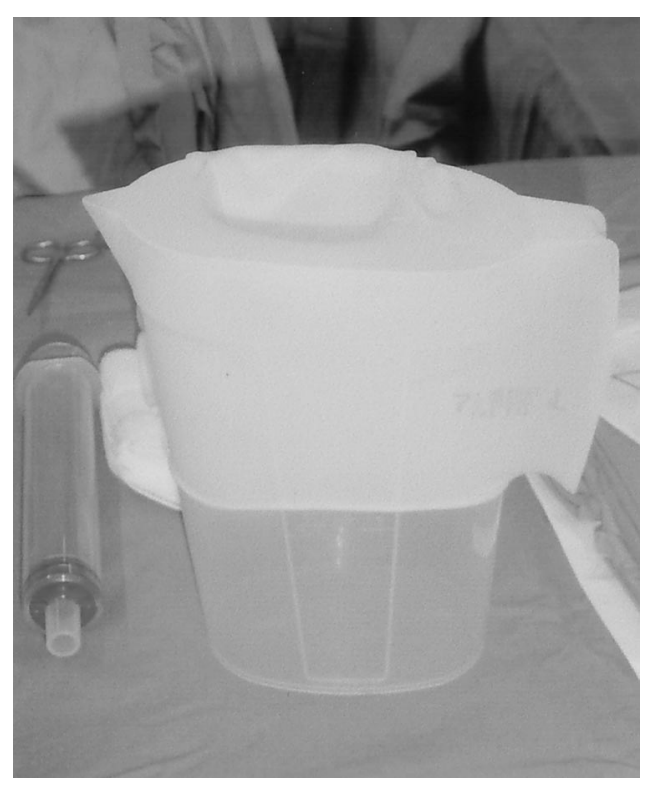

FIG. 1. A large surgical glove is stretched over the top of the jug to seal it.

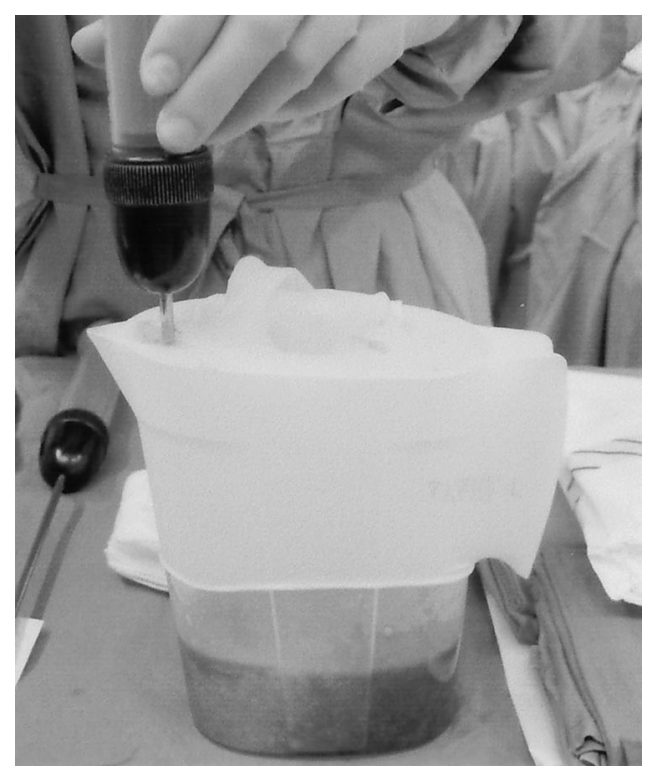

FIG. 2. To evacuate the contents of the syringe into the "closed" jug, the tip of the cannula is passed through an incision made in the glove. ceum, Brucella, Chlamydia, and Rickettsia. These potential risks have been reduced by the use of filters on machine-driven suction systems. No such safeguards exist for syringe-based systems.

The transfer of fat-fluid mix from syringe to measuring jug or other such container carries such a risk of aerosolizing potentially infectious agents. We describe a simple and costeffective measure to reduce the risk to the operating room staff and to prevent spillage of fat-fluid mix in subsequent transfer.

We use a measuring jug to receive the discarded fat-fluid mix. Before use, the container is prepared by stretching a large surgical glove over the top of the jug (Fig. 1). A single stab incision is made in the tensioned membrane. When evacuating the contents of a syringe-based liposuction system, the tip of the cannula is passed through this hiatus into the "closed" jug (Fig. 2). Fat-fluid mix can then be rapidly expelled with minimal risk to staff. In the event that the jug is knocked over, this system also prevents significant spillage. This technique does not interfere with surgical technique or inhibit the ability to measure the volume aspirated. It does not significantly reduce the rate at which the procedure can be performed.

We present a simple and cost-effective technique to reduce the risk of aerosolization of pathogenic agents during syringe liposuction. This reduces the potential risk to operating room staff without adversely affecting the operative time.

DOI: 10.1097/01.PRS.0000089284.65246.52

James A. Haeney, M.R.C.S.
Alastair J. Platt, F.R.C.S.(Plast.)
Department of Plastic and Reconstructive
Castle Hill Hospital
East Yorkshire, United Kingdom
Correspondence to Dr. Haeney
7 Melton Grove
West Bridgford, Nottingham NG2 7NX
United Kingdom
jameshaeney@doctors.net.uk

\section{REFERENCES}

1. Teimourian, B., and Fisher, J. B. Suction curettage to remove excess fat for body contouring. Plast. Reconstr. Surg. 68: 50, 1981.

2. Teimourian, B., and Rogers, W. B. A national survey of complications associated with suction lipectomy: A comparative study. Plast. Reconstr. Surg. 84: 628, 1989.

3. Teimourian, B., and Adham, M. N. A national survey of complications associated with suction lipectomy: What we did then and what we do now. Plast. Reconstr. Surg. 105: 1881, 2000.

4. Fodor, P. B. Wetting solutions in aspirative lipoplasty: A plea for safety in liposuction (Editorial). Aesthetic Plast. Surg. 19: 379, 1995.

5. Klein, J. A. Tumescent technique for local anesthesia improves safety in large-volume liposuction. Plast. Reconstr. Surg. 92: 1085, 1993.

6. Higashi, H., Matsumata, T., and Hayashi, J. Detection of hepatitis $\mathrm{C}$ virus RNA in the ultrasonic dissector irrigating solution used in liver surgery. Br. J. Surg. 81: 1346, 1994.

7. Cukier, J., Price, M. F., and Gentry, L. O. Suction 
lipoplasty: Biohazardous aerosols and exhaust mist-the clouded issue. Plast. Reconstr. Surg. 83: 494, 1989.

\section{GESTATIONAL GIGANTISM AFTER REDUCTION MAMMAPLASTY}

Sir:

Drs. Ahčan, Šolinc, and Meglič offer a dramatic case of "Gestational Gigantism after Reduction Mammaplasty." They present a case report of a patient who developed bilateral generalized enlargement during pregnancy, 4 years after a reduction mammaplasty. They declare that, to their knowledge, "no such case has been previously reported."

Dr. Shulman of Israel and I reported in the British Journal of Plastic Surgery in 1971 two cases of massive breast hypertrophy following reduction mammaplasty. ${ }^{2}$ One was a virginal 16-year-old female patient who developed spontaneous progressive asymmetric enlargement of her breasts, and the other was a 22-year-old mother of one who developed unremitting massive breast hypertrophy during pregnancy.

Both patients had previously undergone breast reduction for unexplained massive hypertrophy. Both women required amputation, with one ultimately accepting prosthetic reconstruction.

While I call this to the attention of the authors for the sake of accuracy in reporting, I must take this occasion to appeal to all authors to do a thorough literature review before declaring originality.

DOI: 10.1097/01.PRS.0000089285.40725.64

Arthur G. Ship, M.D. 1049 Fifth Avenue New York, N.Y. 10028

\section{REFERENCES}

1. Ahčan, U., Šolinc, M., and Meglič, L. Gestational gigantomastia after reduction mammaplasty: Complication or coincidence? Plast. Reconstr. Surg. 111: 956, 2003.

2. Ship, A. G., and Shulman, J. Virginal and gravid mammary gigantism: Recurrence after reduction mammaplasty. Br. J. Plast. Surg. 24: 396, 1971.

\section{REPLY}

Sir:

Dr. Ship kindly commented on our article, "Gestational Gigantism after Reduction Mammaplasty" (Plast. Reconstr. Surg. 111: 956, 2003), and appealed to all authors to do a thorough literature review before declaring originality.

In reviewing the literature to prepare our case report, we read a very interesting article entitled "Virginal and Gravid Mammary Gigantism: Recurrence after Reduction Mammaplasty." The authors, Dr. Ship and Dr. Shulman, described virginal gigantism in a 16-year-old white female patient with an 8-month history of spontaneously occurring, progressive, asymmetric enlargement of both breasts and the case of a 22-year-old white woman, mother of one, with a 6-month history of unremitting breast enlargement with marked discomfort and tense and tender skin who responded only briefly to a course of testosterone and Norluten (Parke-Davis, Morris Plains, N.J.).

In both cases, physical examination revealed typical signs and symptoms of mammary gigantism. In both patients, a reduction mammaplasty was followed by early massive recurrence. In the first case, 6 months postoperatively, the breast had enlarged to equal the preoperative size; and in the second case, approximately 3 months after the operation, progressive breast enlargement became apparent, with alarming enlargement during pregnancy 9 months later. Complete subcutaneous amputation was performed in both cases 6 and 10 months after the original reduction mammaplasty.

In our article, we presented a case report of a 23-year-old healthy white woman who came to our department because of marked ptosis and medium-sized hypertrophy of her breasts. There were no signs or symptoms of sudden unremitting massive hypertrophy, tense and tender skin, or marked discomfort. No facts of medical significance in either her obstetrical/gynecological or family history have been found, and she was on no medication.

The ptosis and mammary hypertrophy were noted, and a standard bilateral breast reduction was performed using the McKissock technique. The postoperative period was unremarkable. However, 4 years later, she presented 10 weeks pregnant to the emergency room unit of the obstetrics/gynecology department with a history of sudden and painful enlargement of her breasts beginning days earlier (typical signs and symptoms of mammary gigantism/gravid macromastia). In the next 48 hours, she came to our outpatient clinic with the question, "Is this a late complication of reduction mammaplasty or just a coincidence?" After discussions with her gynecologist and endocrinologist, urgent curative surgical treatment (total mastectomy) was performed. The following explanation was given: Juvenile (adolescent or virginal) hypertrophy or adolescent macromastia is an uncommon event wherein a young girl, after a normal puberty, has continued breast growth and enlargement even into mature years. The breasts do not decrease in size, and a reduction mammaplasty is required. Even more rare is gravid macromastia, which develops rapidly after the onset of pregnancy. As for adolescent macromastia, the exact cause is unknown, but once established, it occurs with each subsequent pregnancy and all breast tissue should be removed.

This case report is different from that of Dr. Ship and Dr. Shulman in that the initial presentation was for mammary hypertrophy requiring a standard reduction mammaplasty. The onset of mammary gigantism was 4 years subsequent to this operation, during the initial trimester of the patient's first pregnancy. If the patient had come to the first visit with sudden, progressive, massive hypertrophy and tense and tender skin (as was the case in both of Dr. Ship's patients), we would have suggested to her the appropriate treatment, total mastectomy and immediate reconstruction instead of a reduction mammaplasty.

Uroš Ahčan, M.D., Ph.D. Zaloška 7

Ljubljana, Slovenia

\section{REFERENCE}

1. Ship, A. G., and Shulman, J. Virginal and gravid mammary gigantism: Recurrence after reduction mammaplasty. Br. J. Plast. Surg. 24: 396, 1971.

\section{ULTRASOUND ASPIRATION FOR GYNECOMASTIA}

Sir:

In their article "Classification and Management of Gynecomastia: Defining the Role of Ultrasound-Assisted Aspi- 
ration" (Plast. Reconstr. Surg. 111: 909, 2003), Rohrich et al. present a series of 61 patients seen over a period of 14 years. "We offer ... the role of ultrasound-assisted liposuction as a superior method for safe and effective removal of male breast tissue, based on our experience with 61 patients evaluated and treated for gynecomastia from 1987 to 2000." However, only the last 4 years, or about 17 cases, assuming even distribution through the years, are applicable to the main thrust of the article-the role of ultrasound-assisted liposuction. "Ultrasound-assisted liposuction ... has recently emerged as the preferred technique for management of gynecomastia." In support of their contention, the authors use another of their own publications as the only applicable supporting reference. "Several studies have confirmed the selective emulsification of fat leaving higher density structures . . relatively undamaged using ultrasound-assisted liposuction. At higher energy settings, ultrasound-assisted liposuction is effective in removal of the dense, fibrotic parenchymal tissue," they state, without supportive evidence and in clear contradiction of their previous statement.

"More recently, ultrasound-assisted liposuction has emerged as the preferred surgical technique for most cases of gynecomastia, providing minimal scarring and efficient removal of both glandular and fibrotic breast tissues," the authors state, without supporting evidence. They present Courtiss's study claiming a high complication rate with excisional techniques. These complications include overresection, underresection, hematoma, seroma, and unattractive scarring, which are complications that ultrasound-assisted liposuction allegedly avoids. But are complications not adverse events that occur despite a properly executed procedure? Certainly overresection and underresection are technical errors, not complications. All the authors' cases show underresection of the gynecomastia. Seromas and hematomas respond to meticulous technique and proper drainage in most cases but may occur despite proper technique. And the unattractive scarring associated with skin reduction is the same with excisional technique and ultrasound-assisted liposuction, as demonstrated by the authors' Figure 6, where even they accept skin excision 6 to 9 months after the original procedure.

The authors also present a classification system for gynecomastia. For all grades of gynecomastia, ultrasound-assisted liposuction is their treatment of choice. I suggest that a more useful classification takes into consideration three factors: fat versus glandular tissue and skin elasticity. Fat can be excised or suctioned (whatever technique), glandular tissue requires excision (as the authors' pictures show), and skin elasticity is either adequate, borderline, or poor. If skin elasticity is adequate or borderline, the inferior circumareolar incision works well. In borderline cases, skin resection may occasionally be necessary after about 6 months. With poor elasticity (as in their Fig. 6), immediate skin resection will prevent the need for a certain second procedure. I see no compelling evidence presented by the authors that ultrasound-assisted liposuction removes glandular tissue or that it offers any benefit over traditional liposuction for fat contouring.

The preoperative and postoperative photographs provide conclusive evidence that ultrasound-assisted liposuction is ineffective for glandular tissue removal. The preoperative photographs all show gynecomastia. The postoperative photographs all show gynecomastia, though to a lesser degree due to fat removal. The postoperative photograph in Figure 3 shows more gynecomastia than the preoperative photograph in Figure 2. The inframammary scars visible on the photographs are more apparent than the usual infra-areolar incisions with the open technique. The patient shown in Figure 6 needed extended skin resection and still does. Since gynecomastia is an all-or-none process, like pregnancy, and differs only by the degree apparent, the authors' photographs present conclusive evidence that ultrasound-assisted liposuction alone provides unsatisfactory results for glandular gynecomastia.

In their questionable exuberance over the use of ultrasound-assisted liposuction, the authors forgot that it is not the technique but the result that counts. Their results fall short of desirable and obtainable.

DOI: 10.1097/01.PRS.0000089287.94099.B7

Eugene J. Strasser, M.D. 1505 University Drive

Coral Springs, Fla. 33071

\section{REPLY}

Sir:

We appreciate Dr. Strasser's interest in our article, "Classification and Management of Gynecomastia: Defining the Role of Ultrasound-Assisted Liposuction (Plast. Reconstr. Surg. 111: 909, 2003). His comments are duly noted, but his conclusions are somewhat misguided and perplexing. Our article focused primarily on ultrasound-assisted liposuction as another modality available for plastic surgeons to use in the management of gynecomastia. The excellent discussion by Dr. Mladick (Plast. Reconstr. Surg. 111: 924, 2003) serves as an important statement of variations in aesthetic goals and techniques. There are numerous appropriate methods to obtain correction of gynecomastia. To this consideration, we challenged our previous notion that mere correction was adequate. We presented a technique based on our experience that has evolved to be our preferred method.

As with any board-certified plastic surgeon who gains experience in cosmetic surgery procedures, improvements or changes in particular techniques evolve simultaneously with an appreciation for a more mature aesthetic ideal. Our initial goals for elimination of all male breast tissue were supplanted by an ideal for optimal contouring and restoration of a normal male breast contour. We are attentive to our gynecomastia patients who have told us that they do not like diminution or loss of their masculine silhouette. They still want some central breast and areola fullness and desire no indentation or contour depression in their central breast area. Our satisfaction rate has been exceedingly high using ultrasound-assisted liposuction.

Dr. Strasser is quick to condemn the authors' long-term experience with ultrasound-assisted liposuction, both the modality of treatment and the results. First, he suggests that the authors state "without supportive evidence and in clear contradiction of their previous statement" regarding the selective emulsification of fat at lower ultrasound-assisted liposuction settings and improved efficacy in removal of dense glandular tissue at higher settings. This claim largely ignores the published works by Zocchi, ${ }^{1}$ Gingrass, ${ }^{2-4}$ Maxwell, ${ }^{3}$ Kenkel, ${ }^{4,5}$ and Rohrich. ${ }^{4,5}$ The only “contradiction” is Dr. Strasser's dismissal and the overwhelming evidence to support the contrary.

Second, he claims that presented photographs "present conclusive evidence that ultrasound-assisted liposuction alone provides unsatisfactory results for glandular gynecomastia." On what is he basing his assertions, a displeasing, 
overresected chest contour? Indeed, our emphasis was a restoration of a normal male chest contour, not its elimination. If studies show that up to 65 percent of all males have some form of gynecomastia, are we as plastic surgeons operating on 65 percent of male chests, or even half that number? More likely is that we are seeing severe cases and that "normal" constitutes a wide range of appearances, most with some glandular and fat excess. Dr. Strasser's claim that "gynecomastia is an all-ornone process, like pregnancy, and differing only by the degree apparent" demonstrates a clear confusion of his own terminology or a lack of understanding of the disease. The importance of aesthetic balance and the appreciation of proportional improvement have been welcome advancements in the field of rhinoplasty. Should we not embrace these principles when approaching the treatment of gynecomastia? By shifting our surgical goal to be optimal contouring and shape and not merely the "all-or-none" correction as suggested by Dr. Strasser, we leave behind the antiquated notion that normal males have no breast tissue.

Dr. Strasser stated, "It's not the technique but the result that counts." Taking this one step further, the result is not dependent upon the technique that is applied. The result is directly proportional to the talents, skill, and artistry of the surgeon, no matter what technique is used. Many plastic surgeons can obtain excellent results using many types of modalities, including traditional liposuction and/or excision. Our technique using ultrasound-assisted liposuction provides the surgeon with another excellent option to use for management of this common problem in males.

We are aware of Dr. Strasser's enthusiasm for "objective grading systems" for the evaluation of cosmetic surgery. ${ }^{6} \mathrm{He}$ assigns a differential point system based upon his own subjective hierarchy of good and bad features of a postoperative result. We have attempted to precisely demonstrate our experience and the evolution of our technique. However, this subjective standard imposed by Dr. Strasser prevents his concurrence. Evidently, from his evaluation through a perplexing point system, the "results fall short of desirable and obtainable." We acknowledge him for his personal standards, but we invite him to share his experience of gynecomastia surgery with the plastic surgery community. We strongly urge him to show his technique and long-term results, with or without liposuction. By publishing a scientific, clinical article in a peer-reviewed journal, other plastic surgeons could compare his results to those in the literature.

We eagerly look forward to Dr. Strasser's publication in the Journal. In life, as in plastic surgery, it is always better to practice what you preach.

\author{
Rod J. Rohrich, M.D. \\ Department of Plastic Surgery \\ University of Texas Southwestern Medical Center \\ 5323 Harry Hines Boulevard, E7.212 \\ Dallas, Texas 75390-9132 \\ rod.rohrich@utsouthwestern.edu
}

\section{REFERENCES}

1. Zocchi, M. L. Ultrasonic-assisted lipoplasty: Technical refinements and clinical evaluations. Clin. Plast. Surg. 23: 575, 1996.

2. Gingrass, M. K., and Shermak, M. A. The treatment of gynecomastia with ultrasound-assisted lipoplasty. Perspect. Plast. Surg. 12: 101, 1999.

3. Maxwell, G. P., and Gingrass, M. K. Ultrasound-assisted lipoplasty: A clinical study of 250 consecutive patients. Plast. Reconstr. Surg. 101: 189, 1998.
4. Kenkel, J. M., Gingrass, M. K., and Rohrich, R. J. Ultrasound-assisted lipoplasty: Basic science and clinical research. Clin. Plast. Surg. 26: 221, 1999.

5. Kenkel, J. M., Robinson, J. B., Beran, S. J., et al. The tissue effects of ultrasound-assisted lipoplasty. Plast. Reconstr. Surg. 102: 213, 1998.

6. Strasser, E. J. Application of an objective grading system for the evaluation of cosmetic surgical results. Plast. Reconstr. Surg. 109: 1733, 2002.

\section{EFFECTS OF REDUCTION MAMMAPLASTY ON PULMONARY FUNCTION AND SYMPTOMS OF MACROMASTIA}

Sir:

I read with interest the recent article by Sood et al. ${ }^{1}$ and acknowledge their effort in producing a good article on a contentious subject. Indeed, there is a lack of evidence base in the selection criteria for breast reduction surgery that has led to the rationing of health in this aspect of breast surgery across the world. The difficulties with third-party insurance in this respect are also well documented. It is, therefore, a timely contribution and adds to the body of evidence another instance of quantitative benefit of reduction mammaplasty.

A significant finding in this study is the fact that patients benefit from this procedure regardless of body mass index, which unfortunately is still being used to select patients for this procedure. This indeed has also been confirmed by other studies. ${ }^{2}$

The number of patients in this study is a significant improvement on previous work done in this area, and the use of a well-validated respiratory function questionnaire gives further validity to their work.

From a critical viewpoint, however, this work has a demerit that also affects almost all research done in breast reduction, namely, the absence of level 1 or 2 a evidence (lack of any randomized work). This is illustrated by the absence of an adequate control group (i.e., those who have macromastia but do not have an early operation). An addition of a suitable control group will eliminate the confounding factor posed by learning effect, because it could be argued that the instructions for respiratory function test can be learned, thus explaining improvement in some of the voluntary parameters.

Also, although efforts were made to standardize the test for all patients, no mention was made of the time of day when these tests were carried out. It is well known that there is a diurnal variation in respiratory function of up to 10 percent in healthy subjects. ${ }^{3}$

DOI: 10.1097/01.PRS.0000089289.06874.AB

O. C. Iwuagwu, M.B., B.S., F.R.C.S.
Academic Surgical Unit
University of Hull
Castle Hill Hospital
Castle Road, Cottingham
East Riding HU16 5JO, United Kingdom

\section{REFERENCES}

1. Sood, R., Mount, D. L., Coleman, J. J., III, et al. Effects of reduction mammaplasty on pulmonary function and symptoms of macromastia. Plast. Reconstr. Surg. 111: 688, 2003.

2. Zubowski, R., Zins, J. E., Foray-Kaplon, A., et al. Relationship of obesity and specimen weight to complica- 
tions in reduction mammaplasty. Plast. Reconstr. Surg. 106: 998, 2000.

3. Brewis, R. A. L., Gibson, G. J., and Geddes, D. M. (Eds.). Respiratory Medicine. London: Baillière Tindall, 1990.

\section{REPLY}

Sir:

The article by Sood et al. ${ }^{1}$ was interesting to read. Dr. Iwuagwu raises three reasonable objections. The first one concerns the lack of a control group. This is both a legitimate comment and one that is difficult for surgeons to address due to practice and ethical issues. It is one thing to randomly assign patients to receive one of two pills, each of which could benefit them. It is another thing to randomly operate on patients or not. The proportion of articles that I read that have random assignment to surgery for patients is quite small-animals, yes, but patients, no. You certainly cannot conduct a double-blind study where neither the surgeon nor the patient knows what happened. Here, I think one simply has to do the best with what one has.

The second comment concerns the possible learning effect. That is always a possibility. However, I note that the forced expiratory volume in 1 second did not increase, and it would seem that it would be subject to a learning effect if a sizable one exists.

Unfortunately, I am not familiar with the tests that were significant (maximal voluntary ventilation, inspiratory capacity, and peak expiratory flow rate). In the past, I have worked on studies of the effect of smog and cigarette smoking in Los Angeles. The physicians I worked with there mainly examined forced expiratory volume in 1 second, forced vital capacity, and forced expiratory flow 25/75 and preferred forced expiratory volume in 1 second for most of their work. They (Dr. Tashkin and Dr. Gong) were knowledgeable about what measurements should be used depending on the purpose of the study.

We did not correct for time of day in those studies, but they were conducted on large groups of people. Again, if this is a problem, it did not show up in forced vital capacity, forced expiratory volume in 1 second, or forced expiratory flow. A plus in this study, as far as I can see, is that they did take multiple measurements both before and after the operation so they could assess change in several pulmonary measures.

I apologize for not being knowledgeable about the tests that were significant. The authors do explain on pages 692 and 693 of the article what these three tests measure. If you wish to go further with this, I would suggest consulting with a pulmonary physician concerning the problem. I think the major issue is whether or not it makes physical sense that three particular measurements changed following the breast reduction operation.

Virginia Clark, Ph.D. 852 Sporseen Road Sequim, Wash. 98382 clark@olympus.net

\section{REFERENCE}

1. Sood, R., Mount, D. L., Coleman, J. J., III, et al. Effects of reduction mammaplasty on pulmonary function and symptoms of macromastia. Plast. Reconstr. Surg. 111: 688, 2003.

\section{SOFT-TISSUE SARCOMA ARISING FROM A TISSUE NECROSIS CAUSED BY AN INTRAMUSCULAR INJECTION OF DICLOFENAC}

Sir:

In our city, we have been observing occasional cases of tissue necrosis associated with intramuscular administration of diclofenac. In the literature, also, there are some reports showing the same fact. ${ }^{1-4}$ The manufacturers discourage its use in the arm but advocate it in the gluteal region, where the muscle bulk is thicker.

Here we report on a unique case conducted in our department. In December of 2000, a 45-year-old dark-skinned woman received a diclofenac injection in the right gluteal region to treat cold symptoms. Shortly after that, a chronic inflammation developed at the injection site, and then a nodule appeared in the same area. It is important to say that, according to the patient, there was nothing abnormal in this region before the injection. Initially, the primary care surgeon thought it could be an abscess, so some unsuccessful

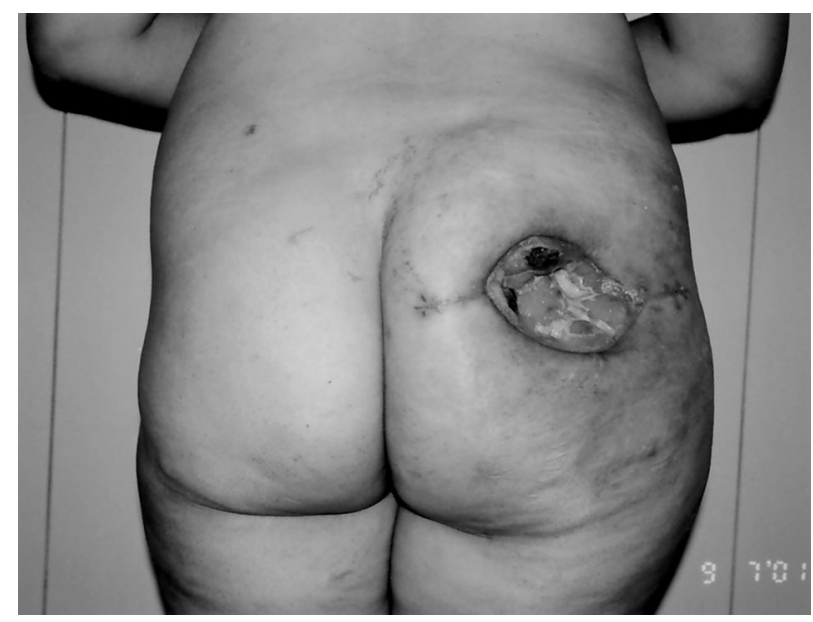

FIG. 1. Preoperative view of the ulcerated mass in the right gluteal region.

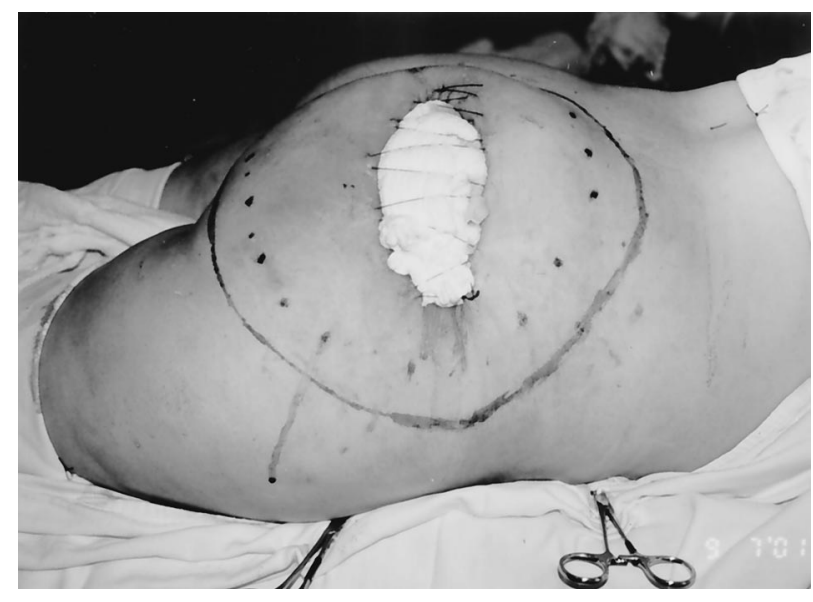

FIG. 2. Perioperative view of the patient in the ventral decubitus position. There is a tie-over dressing over the ulceration. The dotted line corresponds to the mass on palpation. The outer line depicts the 3-cm margin around tumor (line of resection). 
drainage attempts were made. With the lesion increasing in size, the primary care physician decided to refer the patient to our care.

When we first evaluated the patient, there was a $10-\mathrm{cm}$ ulcerated mass in the right gluteal region (Fig. 1). A computed tomography scan demonstrated the tumor mass inside the gluteus maximus muscle and ulceration through the skin. An incisional biopsy in May of 2001 revealed high-grade malignant histiocytoma (grade 3 ). The preoperative staging (liver and chest computed tomography scans and liver function tests) did not show signs of metastatic disease (American Joint Committee on Cancer stage IIIB, T2N0M0). We decided on surgical treatment and performed a segmental resection in

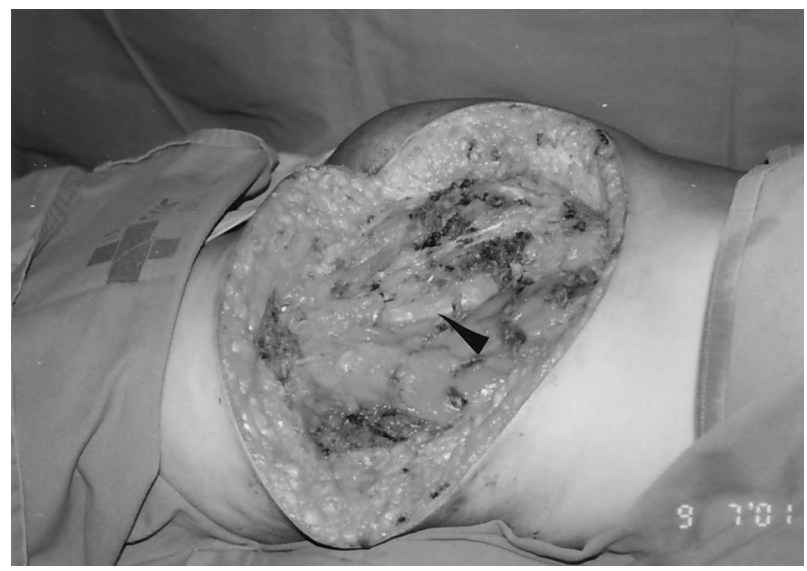

FIG. 3. Perioperative view of the right gluteal region after tumor resection. The arrow designates the sciatic nerve.

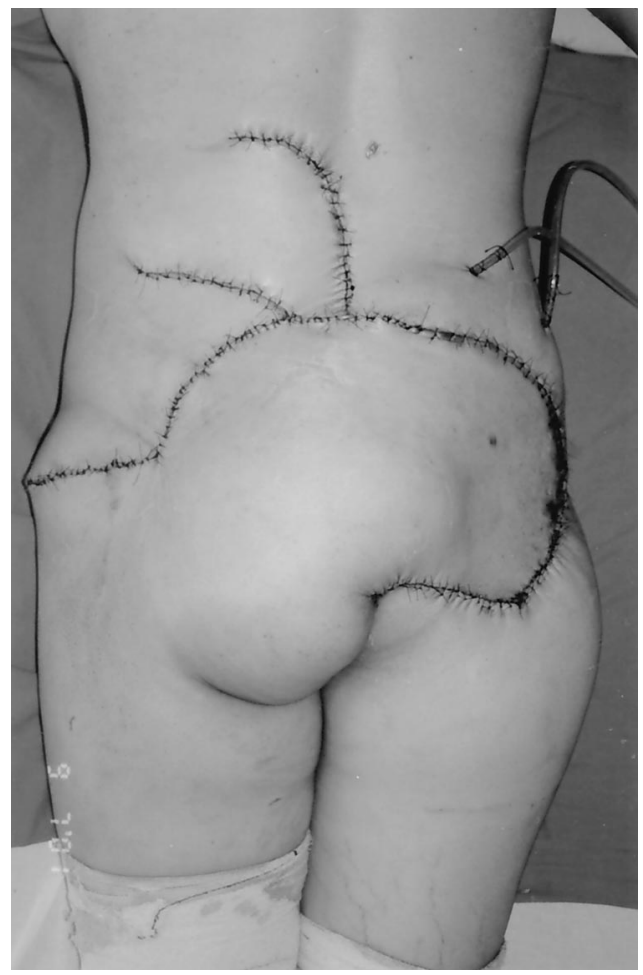

FIG. 4. Postoperative view after fasciocutaneous flap rotation; suction drains are in place. which the tumor was removed en bloc with all the right gluteal muscle and skin above it. A 3-cm safety margin around the tumor was achieved (Figs. 2 and 3). The defect was covered with local fasciocutaneous flaps from the contralateral side (Fig. 4). She had a partial dehiscence in the flap extremity, which healed uneventfully with dressings. The patient received postoperative radiotherapy (cobalt 60, total dose of 5000 cGy divided in daily doses of 200 cGy) with good tolerance.

Unfortunately, in December of 2002, she presented with a local recurrence (confirmed by biopsy). A computed tomography scan demonstrated chest and liver metastasis and tumor invasion of sacrum bone and spinal nerve roots (L5 to S1). In February of 2003, she died of multiorgan failure syndrome associated with systemic disease.

As we said before, we have been seeing some cases of tissue necrosis associated with diclofenac injections, but this is the first time we have seen a malignant tumor developing from this kind of lesion. There are some reports in the literature associating soft-tissue sarcomas (especially those in the extremities) with tissue trauma and chronic inflammation. ${ }^{5}$ Did that happen in this case? It is a question to be answered. Because the interval between the diclofenac injection and the onset of the malignant mass was relatively short, some could say the malignancy was present before the injection.

DOI: 10.1097/01.PRS.0000089290.92476.24

\author{
Marcelo Mayrink, M.D. \\ Albert Christian Mendonça, M.D. \\ Paulo Roberto da Costa, M.D. \\ Department of Plastic and Reconstructive Surgery \\ Hospital Público Regional de Betim \\ Betim, MG, Brazil \\ Correspondence to Dr. Mayrink \\ Department of Plastic and Reconstructive Surgery \\ Hospital Público Regional de Betim \\ Av. Edméia Matos Lazarotti, 3800 \\ 32632-090 Betim, MG, Brazil \\ mmayrink@hotmail.com
}

\section{REFERENCES}

1. Rygmstad, T., and Kvan, A. M. Streptococcal myositis and tissue necrosis with intramuscular administration of diclofenac (Voltaren). Acta Anaesthesiol. Scand. 39: 1128, 1995.

2. Verfaillie, G., Knape, S., and Corne, L. A case of fatal necrotizing fasciitis after intramuscular administration of diclofenac. Eur. J. Emerg. Med. 9: 270, 2002.

3. Pillans, P. I., and O'Connor, N. Tissue necrosis and necrotizing fasciitis after intramuscular administration of diclofenac. Ann. Pharmacother. 29: 264, 1995.

4. Giovannetti, M., Machado, M. A., Bonelli, M., Jr., Ikejiri, C. I., Alonso, N., and Branco, P. D. Tissue necrosis: A side effect of sodium diclofenac: Report of cases and discussion of the physiopathology (in Portuguese). Rev. Hosp. Clin. Fac. Med. São Paulo. 48: 39, 1993.

5. Lewis, J. J., and Brennan, M. F. Soft tissue sarcomas. Curr. Probl. Surg. 33: 826, 1996. 


\section{A RARE CASE OF DERMOID GYST BEHIND THE EAR}

Sir:

A 39-year-old Turkish man presented with a postauricular cyst that had been present since childhood (Fig. 1). The computed tomography scan revealed an encapsulated tumor with no intracranial extension.

A surgical excision of the mass was carried out with the patient under general anesthesia. The cyst contained mucoid fluid and keratin. The histologic examination confirmed that the lesion was a dermoid cyst. A good cosmetic result was obtained with direct skin closure.

The most accepted theory about dermoid cysts was postulated by New and Erich ${ }^{1}$ and states there is a congenital "inclusion" of germ layers in the deeper tissues along the line of embryonic fusion. The disorganized growth and differentiation of these sequestered cells give rise to dermoid cysts. Dermoid cysts can be divided into three distinct histologic types, depending on their histological appearance: epidermoid, dermoid, and teratoid. Epidermoid cysts contain laminated keratinous material and have no sebaceous glandular structures in their lining. Dermoid cysts are subcutaneous tumors lined by stratified squamous epithelium and contain cutaneous appendages such as hair follicles, sebaceous glands, and sweat glands in variable amounts. Teratomas are true neoplasms arising from totipotent cells and contain representative cells from all three embryonic germ layers.

The differential diagnosis of a postauricular cyst includes an epidermal inclusion cyst, a trichilemmal cyst, lipoma, and a hemangioma. Trichilemmal or sebaceous cysts clinically resemble epidermoid cysts. The diagnosis is confirmed histologically with amorphous keratinous material contained in the cystic cavity. Lipomas are common benign soft-tissue adipose tumors and may have the same appearance as dermoid

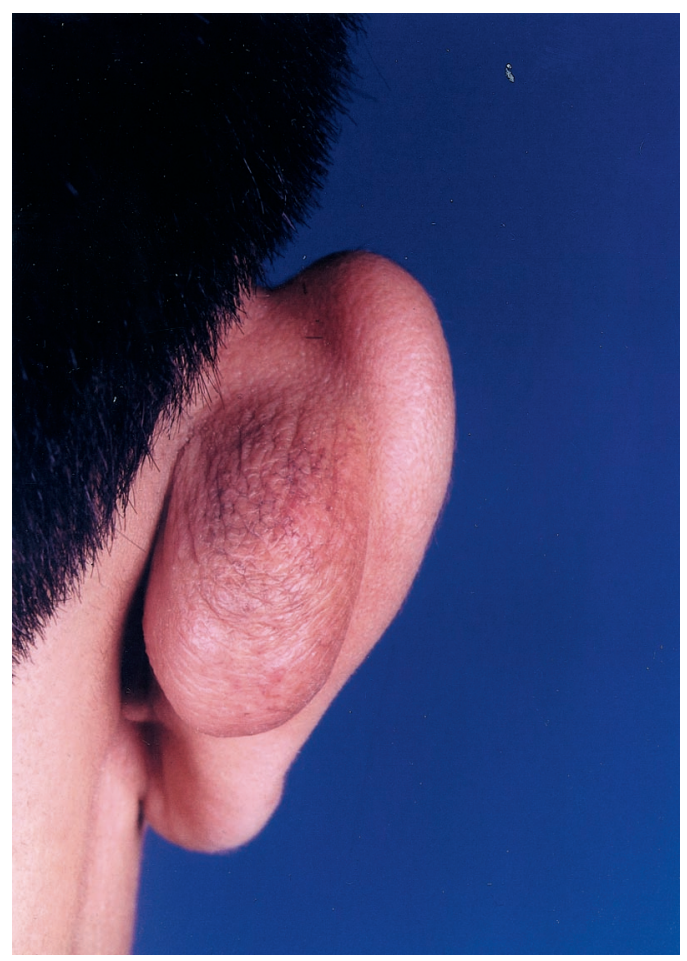

FIG. 1. Lump in postauricular region of the right ear. cysts. Hemangiomas are usually present at birth and are benign tumors of vascular endothelium and can spontaneously involute.

Dermoid cysts are usually present at birth and are predominantly found in males. They are asymptomatic, slowly expanding, unilocular, cystic masses. Most occur in the ovaries, ${ }^{2}$ with less than 7 percent occurring in the head and neck region. ${ }^{3}$

When they occur in the head and neck region, their most common location is the fronto-orbital upper outer quadrant of the orbit. Other locations are the midline of the nose or neck, the sublingual region, and the sternal, perineal, scrotal, and sacral areas. ${ }^{4}$

Dermoid cysts of the auricle are extremely rare. There are only three reported cases of postauricular dermoid cysts, ${ }^{5-7}$ although five cases of auricular dermoid cysts have been reported in the Japanese literature, and they all occurred on the superior pole of the ear. ${ }^{2}$

DOI: 10.1097/01.PRS.0000089334.04867.D8
B. A. De Souza
C. Dey
N. Carver
Department of Plastic and Reconstructive Surgery
The Royal London Hospital
St. Bart's and The Royal London NHS Trust
Whitechapel, London, United Kingdom
Correspondence to Dr. De Souza
88 The Chine
Grange Park
London N21 2EH, United Kingdom

\section{REFERENCES}

1. New, G. B., and Erich, J. B. Dermoid cysts of the head and neck. Surg. Gynecol. Obstet. 65: 48, 1937.

2. Ikeda, M., Muto, J., and Omachi, S. Dermoid cyst of the auricle: Report of two cases. Auris Nasus Larynx 16: 193, 1990.

3. Reddy, V. S. Radhakrishna, K., and Rao, P. L. Lingual dermoid. J. Pediatr. Surg. 26: 1389, 1991.

4. Batsakis, J. G. Teratomas of the head and neck. In Tumors of the Head and Neck: Clinical and Pathological Considerations, 2nd Ed. Baltimore: Williams \& Wilkins, 1979. Pp. 226-232.

5. Samper, A. Dermoid cyst on the auriculotemporal area. Plast. Reconstr. Surg. 106: 947, 2000.

6. Bauer, D. J., Diwan, R., Honig, B. K., and Yokel, B. Large asymptomatic mass on the ear: Dermoid cyst of the auricle. Arch. Dermatol. 130: 913, 1994.

7. Meagher, P. J., and Morrison, W. A. An unusual presentation of bilateral prominent ears. Br. J. Plast. Surg. 54: 366, 2001.

\section{A NEW DEVICE: A PORTABLE AND EFFECTIVE IRRIGATION SYSTEM FOR PRESSURE ULCERS}

Sir:

In the current aging society, pressure ulcers are an important issue in medicine and nursing. Daily prevention and daily treatment are essential to cure a pressure ulcer. Recognizing the prevalence of pressure ulcers and the need for preventive tools, the Agency for Healthcare Research and Quality assembled a 
national interdisciplinary panel to develop a set of best practice guidelines for pressure ulcer prevention. ${ }^{1,2}$ The theory for our new device is described in Figure 1.

The prototype consisted of a funnel, a drainpipe, a portable sprinkler, a hose, and a bucket. In this report, we introduce the new type, which has a hand-made plastic ulcer cup composed of two half-balls and a drainpipe (Fig. 2).

The big half-ball effectively prevents drainage splash. The small half-ball prevents reflux of drainage by allowing the drainage to pool. The portable sprinkler was bought at a low price in a country store. It is better if the portable sprinkler has a mechanism that continues to give pressure to fluid by manual pumping and gripping for continuous spurt.

In the ulcer cup, the drainage point is at the low position of the cup at profile. The hose connects the cup and the bucket. All of the contaminated water is drained into the bucket through the hose (Fig. 3).

We used this system in a hospital on 10 patients with pressure ulcers at the sacral portion. The grade of pressure ulcer according to the National Pressure Ulcer Advisory Panel was stage III or IV. Five months later, one case at stage IV

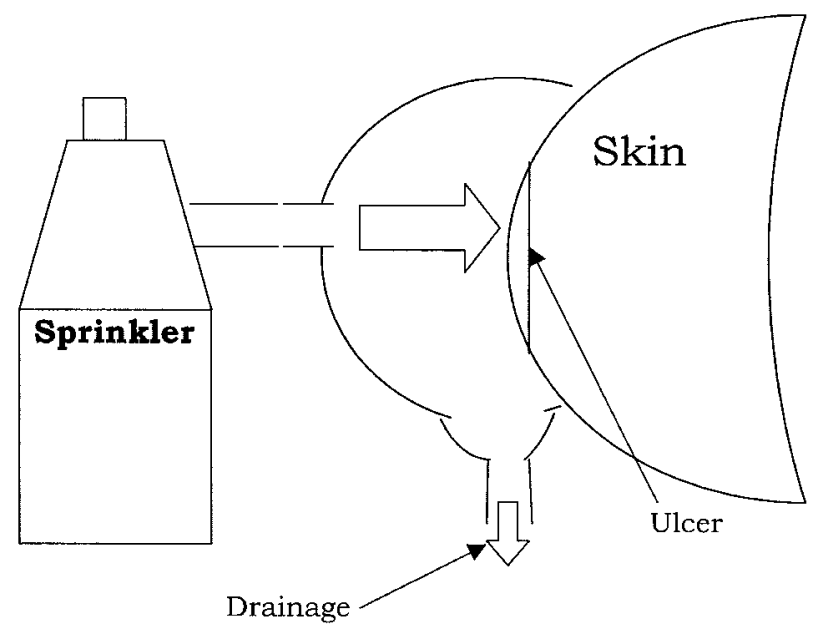

FIG. 1. Diagram of the new irrigation system, showing the course of the water and the placement of the equipment.

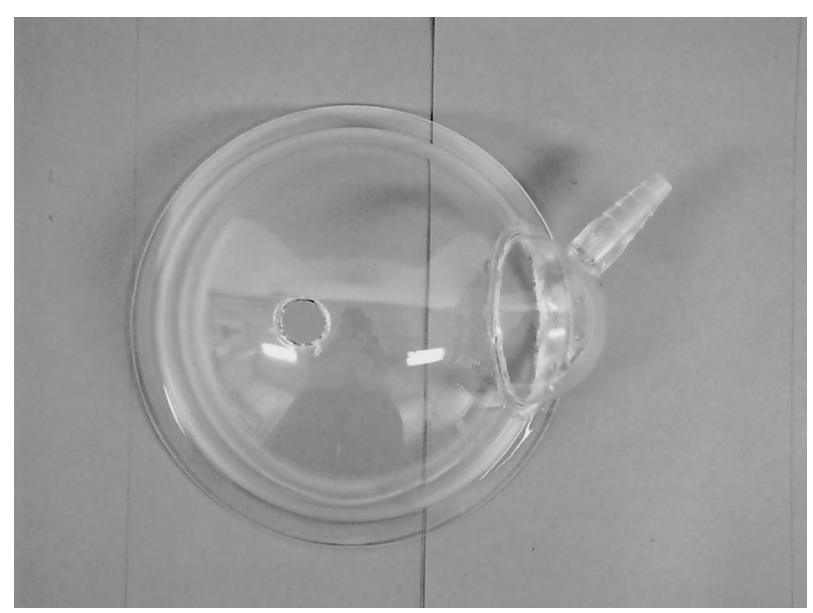

FIG. 2. The ulcer cup is a handmade plastic cup composed of two half-balls and a drainpipe.

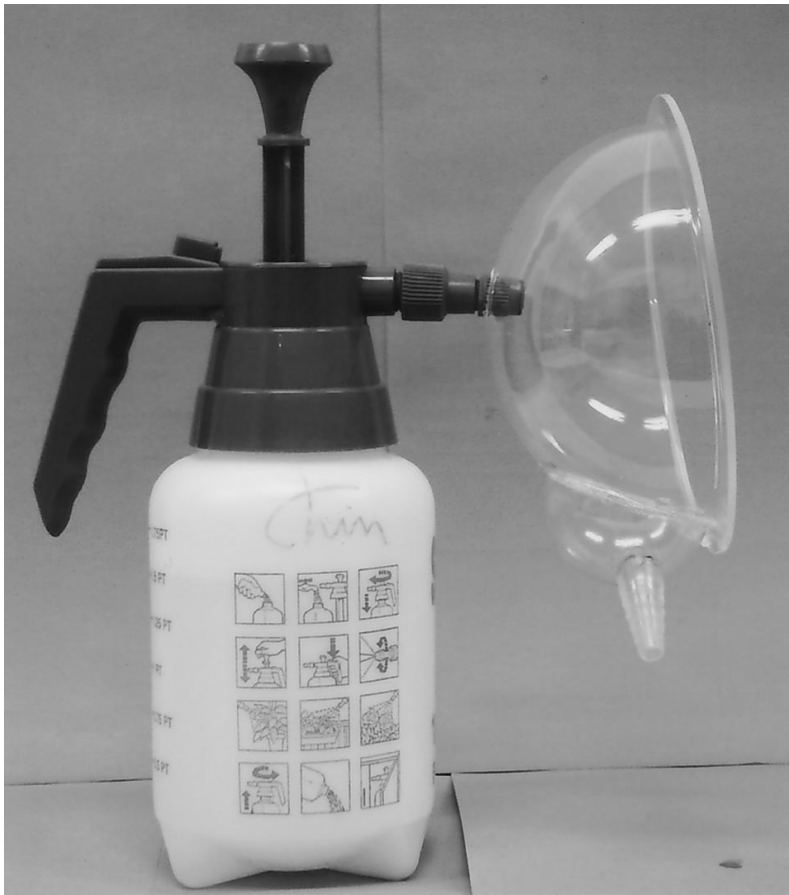

FIG. 3. The irrigation system (hose and bucket are not shown).

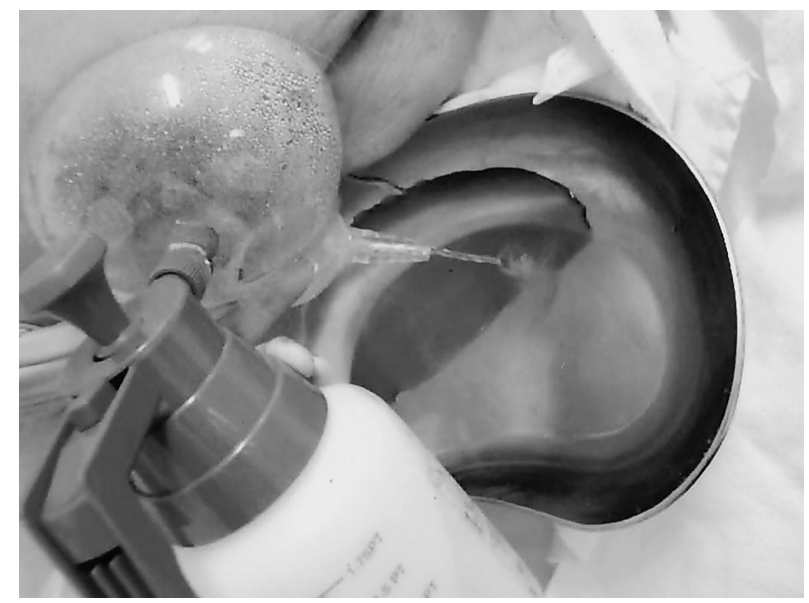

FIG. 4. Clinical application. After the hose is released, contaminated water is drained through the pipe. As shown in the photograph, the new system can be used with one hand.

became stage II, and two cases at stage IV became stage III. The other cases remained at the same stage (Fig. 4).

Pressure ulcer prevention is a key element in nursing. For patients, development of a pressure ulcer is a major source of morbidity, which is associated with an increased risk of death. Once pressure ulcers have occurred, cleansing and débridement are the usual prerequisites to further treatment or ultimate healing, because cleaning the wound of inflammatory stimuli such as devitalized tissue, chemicals, and bacteria involves débridement and cleansing procedures. Generally, it is difficult to treat the pressure ulcers because they are deeply infected. Débridement can be 
accomplished surgically, mechanically (wet-to-dry gauze), or chemically (autolysis or topical enzymes). Several recent studies document the benefits of each of these techniques. Cleansing is the process of using a large volume of fluid to remove loosely adherent foreign material. Numerous wound-cleansing solutions and novel irrigation systems have been introduced in recent years. ${ }^{3}$ Systems and facilities must use additional resources (staff time and treatments) if a patient develops a pressure ulcer. If possible, cleaning the wound by irrigation using a large volume of water with appropriate pressure is not only best but also saves additional resources. Our method addresses this problem. In the literature, there are many reports on irrigation systems, including closed continuous irrigation, ${ }^{4} \mathrm{a}$ dental water irrigation device, ${ }^{5}$ and a portable shower. Irrigation with a shower is one of the best approaches in terms of pressure, but a large volume of water is needed to clean the wound, and naturally, drainage for contaminated water is needed. No reports about irrigation systems consider drainage. Because there are many patients who cannot be easily moved to another place (e.g., treatment room or bathroom) in a hospital or a nursing home, it is very important to use a portable irrigation system for everyday treatment and continuation of care.

We have discovered a new device with which to treat pressure ulcers. The advantages of this system are low cost, portability, reduced time for treatment, ease of use, and control of contaminated drainage.

DOI: 10.1097/01.PRS.0000089334.04867.D8

Takafumi Chin, M.D.

Hiko Hyakusoku, M.D.

Department of Plastic and Reconstructive Surgery Nippon Medical School Hospital

Tokyo, Japan

Correspondence to Dr. Chin

Department of Plastic and Reconstructive Surgery

Nippon Medical School Hospital

1-1-5 Sendagi, Bunkyo-ku

Tokyo 113-8603, Japan

chin@peach.plala.or.jp

\section{REFERENCES}

1. Bergstorm, N., Bennet, M., and Carlson, C. Clinical Practice Guideline Number 3: Pressure Ulcers in Adults: Prediction and Prevention (AHCPR Publication No. 95-0653). Rockville, Md.: U.S. Department of Health and Human Services, Public Health Service, Agency for Health Care Policy and Research, 1994.

2. Debra, S. Adherence to pressure ulcer prevention guidelines. J. Am. Geriatr. Soc. 51: 56, 2003.

3. Rodeheaver, G. T. Pressure ulcer débridement and cleansing: A review of current literature Ostomy Wound Manage. 45: 80, 1999.

4. Takahiro, I. Local continuous irrigation for pressure ulcers of spinal cord injured patients. Jpn. J. P. U. 2: 264, 2000.

5. Nourse, A. M., and Myers, W. Dental water irrigation device used for cleaning decubitus ulcers. Phys. Ther. 58: 1219, 1978.

\section{A DOUBLE POCKET FOR TISSUE EXPANDER IMPLANTATION IN BREAST RECONSTRUCTION}

Sir:

We present a new technique we have used recently in postmastectomy breast reconstruction by a tissue expander implantation. Tissue expansion utilizes the principle of gradual stretching of the chest wall tissue and aims to accommodate a larger implant after a complete mastectomy with large skin loss. ${ }^{1}$ In this kind of reconstruction, the tissue expander is always placed in a submusculofascial position. ${ }^{2}$

To create the usual pocket for the implant, the lateral mastectomy scar is excised, and the dissection is carried down to the pectoralis major muscle; the lateral fibers of the muscle are separated, and the dissection is extended beneath the musculofascial layer. ${ }^{3,4}$ With this technique, we obtain a single submusculofascial pocket ready to accommodate the expandable device.

In August of 2002, a 58-year-old woman presented to our department asking for a breast reconstruction. In 1998, the patient had undergone a complete right mastectomy with total excision of axillary nodes for an intraductal breast cancer; moreover, in 2001, the patient had undergone an aortocoronary bypass to treat an acute heart attack.

At the first visit, our patient presented not only with the usual axillary and transpectoral scars (Fig. 1, $A$ ) but also with a long longitudinal scar in the sternal region due to her previous heart surgery (Fig. 1, B). Because of the lack of soft tissues, we decided to place a tissue expander implant in the usual submuscular pocket.

In the operating room, after excision of the lateral mastectomy scar, the submusculofascial layer was found and elevated to create the submuscular pocket for the tissue expander (Fig. 2, B). During the dissection, however, probably as a consequence of the combination of previous mastectomy and heart surgery, severe fibrosis and fibrotic adherences were found not only under the pectoralis major but also between the muscle and the overlying soft tissue. Thinking about the subsequent difficulty in device expansion due to the poor elasticity of this particular patient's chest wall, we decided on a new procedure; we created a second pocket (Fig. 2, A), placed over the pectoralis major, using a blunt and difficult dissection of the muscle fascia from the overlying fibrotic subdermal layer.

This second pocket was not meant to contain any device but was created to form a mobile layer in the chest wall to help

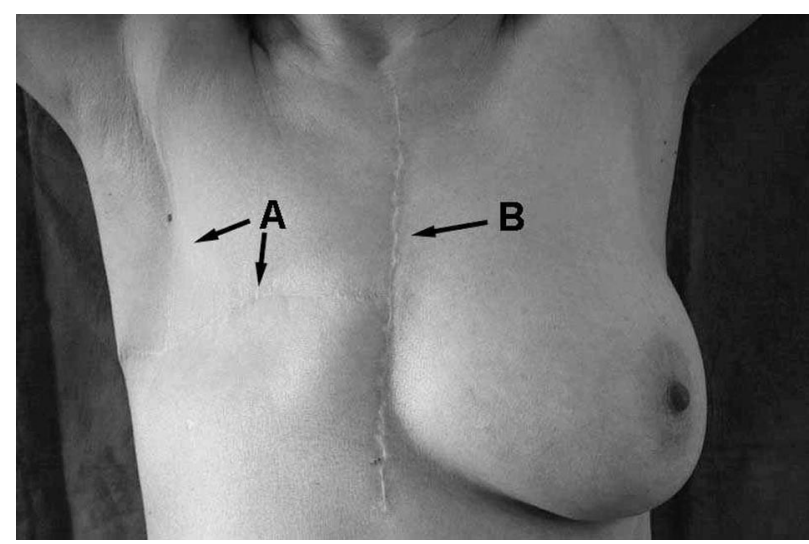

FIG. 1. Preoperative view. A, Axillary and transpectoral scars from previous mastectomy. $B$, Long longitudinal scar in the sternal region due to previous heart surgery. 


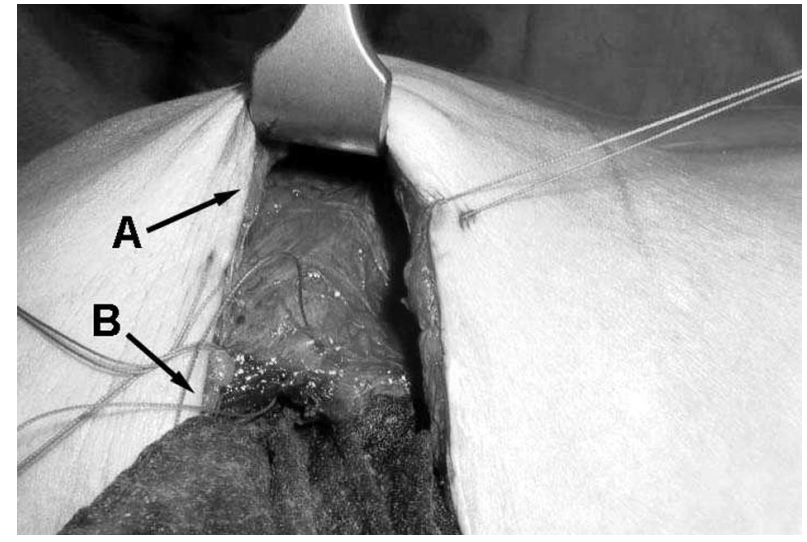

FIG. 2. Intraoperative view. $A$, Supramuscular pocket to increase chest tissue's mobility. $B$, Submusculofascial pocket to accommodate the expandable device (green abdominal gauze fills the pocket).

soft tissues stretch during the expander filling. In this way, we could easily introduce a 500-cc Becker mammary expander, with the fill valve placed laterally in a subcutaneous pocket. The patient was discharged 5 days after the operation, and we started filling the mammary expander about 3 weeks later.

Currently, the expander device is inflated by 290 cc of saline solution, and we have had no trouble during the weekly instillation.

In conclusion, we think that this double-pocket technique for expander implantation can be very helpful for the surgeon, particularly in cases like ours, with a minimal increase in surgical time.

DOI: 10.1097/01.PRS.0000089334.04867.D8

Luigi Valdatta, M.D.

Christian Mortarino, M.D.

Alessandro Thione, M.D.

Mara Buoro, M.D.

Carlo Fidanza

Plastic Surgery Unit

University of Insubria

Ospedale di Circolo

Fondazione Macchi

Varese, Italy

Correspondence to Dr. Valdatta Chirurgia Plastica

Ospedale di Circolo

Viale Borri 57

21100 Varese, Italy

chirplas@libero.it

\section{REFERENCES}

1. Argenta, L. C. Reconstruction of the breast by tissue expansion. Clin. Plast. Surg. 11: 257, 1984.

2. Becker, H. Breast reconstruction using an inflatable breast implant with detachable reservoir. Plast. Reconstr. Surg. 73: 678, 1984.

3. Bostwick, J. Breast reconstruction following mastectomy. Contemp. Surg. 27: 19, 1985.

4. Dick, G. O., and Brown, S. A. Breast reconstruction using modified tissue expansion. Plast. Reconstr. Surg. 76: 613, 1986. 